\title{
http://bjas.journals.ekb.eg \\ The Protective Effect of Ascorbic Acid and Curcumin on the Chronic Toxicity of Meloxicam on the Testis of Adult Albino Rats \\ M.R.Haroun, A.A.Eldin, S.M.EL-Khouly and I.A.Mostafa \\ Clinical Toxicology Dept., Faculty of Medicine, Benha Univ., Benha, Egypt
}

E-Mail:I.Mostafa@gmail.com

\begin{abstract}
Meloxicam is a type of NSAIDs that has more selectivity on COX-2. Rehashed organization of meloxicam was accounted for to instigate testicular poisonousness, while curcumin and ascorbic corrosive have defensive properties against testicular injury. This examination was expected to explore the poisonous impacts of constant meloxicam organization on the testis, assess the part of oxidative worry in this impact and assess the conceivable defensive impact of curcumin and nutrient $\mathrm{C}$ each alone on this harmfulness. For progressive 63 days, grown-up male pale skinned person rodents were designated into 7 gatherings. Gathering A, regulated refined water; bunch B, directed corn oil; bunch C, managed curcumin [100 mg/kg/day intragastric] broke down in corn oil; bunch D, administrated ascorbic corrosive [200 mg/kg/day intragastric] disintegrated in refined water; bunch $\mathrm{E}$, administrated meloxicam $[8 \mathrm{mg} / \mathrm{kg} /$ day intragastric] broke down in refined water; bunch $\mathrm{F}$, administrated intragastric meloxicam and curcumin in similar past portions and gathering $\mathrm{G}$, administrated intragastric meloxicam and ascorbic corrosive in similar past dosages. Blood and testis tissue tests were gathered for biochemical, histopathological, and ultrastructural assessment. The outcomes uncovered that meloxicam organization in high rehashed dosages prompted a critical lessening in testis weight, sperm boundaries, and cell reinforcement movement of testicular tissue. Plasma testosterone level demonstrated non-critical lessening. Histopathological assessment uncovered rounded degeneration, intercellular vaculaization, interstitial edema and blockage of veins. The ultrastructure assessment uncovered cytoplasmic vacuolations and mitochondrial growing of spermatogenic and sertoli cells. Attendant organization of curcumin or ascorbic corrosive with meloxicam improved these changes. End: The outcomes explained the solid defensive impact of curcumin and ascorbic acids each alone on meloxicam prompted testicular harmfulness in rodents at biochemical, histopathological, and ultrastructural levels.
\end{abstract}

Keywords: Meloxicam, Testis, Curcumin, Ascorbic acid, Oxidative stress.

\section{Introduction}

Meloxicam is a commenly utilized medication that has a place with the gathering of non-steroidal calming drugs [NSAIDs] and is recommended much of the time for its pain relieving and mitigating properities intervening its activity on cyclo-oxygenase catalyst decreasing provocative prostaglandins [12] and [17].

Reserchers have perceived that meloxicam adminstration for long peroid may prompt improvement of genuine antagonistic impacts that expansion at high dosages as cardiovascular thrombotic occasions, gastrointestinal ulcers, hepatic and renal hindrance [66] and [18] and [52].

Drawn out utilized of meloxicam was accounted for likewise to create poisonous impacts on male regenerative framework that brought about hindrance of spermatogenesis and testicular degenerative changes [69]. These harmful impacts have been proposed to be vague piece of harmfulness that might be not identified with its impact on prostaglandins creation as past investigations detailed that ripeness has not been influenced in male mice with cyclo-oxygenase chemicals' changes [22].

The oxidative pressure harm of testicular tissue is recommended to assume a significant function in meloxicam-actuated testicular poisonousness [7] on the grounds that oxidative pressure clarified meloxicam harmful impacts on different tissues as stomach, liver and kidney [66], and it is considered as the most significant factor in male infiritily [Barati et al., 2020].

Curcumin is the most organic dynamic part of tumeric rhizomes and is considered as a powerful enemy of oxidant that ensures bio-films against oxidative pressure harm by going about as proton giver, hydrogen peroxide scavanger and superoxide radical age inhibitor [41].

In a years ago, reserches have zeroed in on the defensive impact of curcumin against xenobiotic instigated oxidative pressure harm in different tissues particularly testis [36] and [44]\& [68].

For a long time, ascorbic corrosive was utilized to shield body tissues from lipid peroxidation either legitimately or by restoring the other enemies of oxidants as glutathione and nutrient $\mathrm{E}$ helping in annulling the hurtful impacts of numerous xenobiotics. Likewise, ascorbic corrosive was demonstrated to assume a function in spermatogenesis by dispensing with free radicals that disrubt spermatogenesis and testosterone creation [[45] \& [56].

\section{Aim of the work}

This study was completed to explore the poisonous effect of meloxicam organization in high regular dosages for 63 sequential days on the testis of grown-up pale skinned person rodents, assessing the function of oxidative worry in this impact and the likely defensive part of curcumin and ascorbic corrosive each alone against this poisonousness.

\section{Materials and strategies}

\subsection{Materials}

Synthetic concoctions, Dosage routine and Vehicle:

Meloxicam was bought from "Outpatient" Pharmacy as $15 \mathrm{mg}$ tablet, it was accessible in fluid structure, one tablets of $15 \mathrm{mg}$ was broken up in 150 milliliters of refined water to plan grouping of $0.1 \mathrm{mg} / \mathrm{ml}$. Curcumin [100\%] virtue was bought from Sigma-Aldrich 
organization, Cairo, Egypt, accessible in powder structure. One gm of curcumin was suspended in $100 \mathrm{ml}$ of corn oil. Ascorbic corrosive [100\%] virtue was bought from EL-Gamhureia drug and concoction organization, Cairo, Egypt, accessible in powder structure given in a portion $200 \mathrm{mg} / \mathrm{kg} /$ day. One gm of nutrient $\mathrm{C}$ will be broken down in $100 \mathrm{ml}$ refined water. Packs of glutathione peroxidase [GPx], decreased Glutathione [GSH], superoxide dismutase [SOD], and malondialdehyde [MDA] were bought from Biosymptomatic Co., Dokki, Giza, Egypt.

\section{Creatures}

Seventy grown-up male pale skinned person rodents, weighing between $300-320 \mathrm{~g}$ toward the start of the trial were remembered for this examination. Rodents were took into account transformation [1 week before experiments] at Anatomy Department, Faculty of Medicine, Benha University, to learn their physical prosperity, and to bar any unhealthy creatures. All creatures have gotten a similar eating regimen [wheat, bread and milk] on a timetable of 12 hours of light and 12 hours of dull. The hour of portion organization was fixed for all creatures at 12 P.M.

\section{Creature gathering}

For 63 consecuative days which relate to one spermatogenetic cycle, seventy grown-up male rodents arbitrarily partitioned into seven gatherings, each comprised of 10 creatures, and disseminated as follows:

- Group An: Each rodent was dealt with orally with refined water and given orally by gastric cylinder.

- Group B: Each rodent was treated with corn oil with a volume of $1 \mathrm{ml} / 100 \mathrm{~g}$ once every day and given orally by gastric cylinder.

- Group C [curcumin treated]: Each rodent was treated with curcumin [100 $\mathrm{mg} / \mathrm{kg}$ body weight/day] or [10 $\mathrm{mg} / 100 \mathrm{gm}]$ body weight once every day and given orally by gastric cylinder. The choice of this portion depended on the past examination done by [Oguzturk et al., 2012].

- Group D [vitamin C treated]: Each rodent was treated with $200 \mathrm{mg}$ of nutrient $\mathrm{C} / \mathrm{kg}$ body weight once every day and given orally by gastric cylinder. The determination of this portion depended on the past examination done by [22].

- Group E [meloxicam treated]: Each rodent was treated with meloxicam by portion of $8.4 \mathrm{mg} / \mathrm{kg}$ once every day and given orally by gastric cylinder [representing $1 / 10$ of LD50,the oral middle deadly portion [LD50] of meloxicam in rodents was $84 \mathrm{mg} / \mathrm{kg} \mathrm{b.w}$. as per [36].

- Group F [meloxicam and curcumin treated group]: Each rodent was treated with $100 \mathrm{mg} / \mathrm{kg}$ of curcumin followed by meloxicam $8.4 \mathrm{mg} / \mathrm{kg}$ once every day and given orally by gastric cylinder.

- Group G [meloxicam and nutrient C treated group]: comprises of 10 rodents, each rodent was treated with $200 \mathrm{mg} / \mathrm{kg}$ of nutrient $\mathrm{C}$ followed by meloxicam 8.4 $\mathrm{mg} / \mathrm{kg}$ once every day and given orally by gastric cylinder.

Creatures were dealt with empathetically as per the convention of treatment of trial creatures of Benha Faculty of Medicine and acknowledged by the Research Ethical Board of Faculty of Medicine, Benha University. Rodents were yielded following 24 hours from the last administrated dose.

\subsection{Methods}

Body weight and testis weight:

Rodents' body loads were estimated toward the start of the investigation [before treatment] and recorded, at that point toward the finish of the trial utilizing a touchy parity. After scarification, gonads were taken out and taken from their greasy tissues and veins and their relative loads were estimated.

Blood tests for biochemical investigation [Testosterone hormonal assay]:

Rodents were anesthetized with ether at that point blood tests were taken from the hearts. After that blood tests put in clean cylinders without anticoagulant at that point left at $37^{\circ} \mathrm{c}$ hatchery fifteen minutes. Coagulated blood centrifuged for fifteen minutes at $5000 \mathrm{rpm}$. Sera were placed in the extraordinary cylinders, secured by Parafilm, marked and solidified for 3 days and tried after that for testosterone level estimated by routine research facility tests [radioimmunoassay] [57].

\section{Sperm check and motility}

Both were performed by the method received by [14], utilizing pipette of haemocytometer. The undiluted semen was pulled back from epididymis sufficient 0.1 and the pipette was then topped off to the imprint 101 by typical saline recolored with eosin. The substance of the pipette were blended by holding the finish of the pipette with thumb and forefingers and shaking it energetically. The spread slide was set over the checking chamber and a drop of weakened semen was spread between the haemocytometer slide and its spread. The sperms in 5 huge squares contains [contain 80 little squares] were checked utilizing the powerful target focal point. The sperm cell fixation in cubic milliliters was assessed by duplicating the checked number of sperms by 10 [depth] and 1000 [dilution].The dynamic motility of sperms was analyzed including a little bead of epididymis semen to one drop of sodium citrate arrangement $2.9 \%$ on a warm slide. A few fields were analyzed and the rates of logically motile sperms were assessed and recorded.

Assurance of testis cancer prevention agent action:

\section{Assurance of MDA level}

Lipid peroxidase communicated as MDA level, SOD level, GPx level, and GSH level were resolved in the supernatant utilizing financially accessible colorimetric strategies following the maker instructions.The MDA focus in tissue tests was resolved utilizing the technique depicted by El-[25], by estimating thiobarbituric receptive species. The thiobarbituric corrosive responsive substances respond with MDA in acidic medium at 
temperature $95 \mathrm{C}$ for 30 moment to deliver a pink hued complex, which can be estimated calorimetrically at 534 $\mathrm{nm}$. The SOD fixation in tissue tests was resolved utilizing the technique depicted by [59], by estimating the capacity of the compound to hinder the phenazine methosulphate-intervened decrease of nitroblue tetrazolium color, which can be estimated calorimetrically at $560 \mathrm{~nm}$. The GPx focus in tissue tests was resolved utilizing the strategy portrayed by [47]. The test is backhanded proportion of action of GPx. Oxidized glutathione [GSSG], endless supply of a natural peroxide by GPx is reused to its decreased state by the chemical glutathione reductase [GR]. The oxidation of NADPH to NADP is joined by decline in absorbance at $340 \mathrm{~nm}$ giving spectrophotometric intends to checking GPx action. The GSH fixation in tissue tests was resolved utilizing the technique portrayed by [45]. The strategy dependent on decrease of 5,5 dithiobis-2-nitrobenzoic corrosive with GSH in testicles and epididymis homogenate supernatant to deliver yellow intensify that is straightforwardly corresponding to GSH focus and its absorbance can be estimated at $405 \mathrm{~nm}$.

Histopathological study [light and electron microscope]:

Light magnifying lens

As indicated by Lamberg\& Rothstein [1978], testicles absorbed bouin's answer, which is utilized to fix organs that need great morphologic investigation like testis. Tissue examples were fixed for 6-8 hours and afterward moved to $70 \%$ liquor before submitting to histology for robotized drying out, paraffin implanting, segment, and recoloring at Pathology Department, Faculty of Medicine, Benha University.

\section{Electron magnifying lens}

As indicated by [49], little bits of testicles fixed in $2.5 \%$ glutaralde $\neg$ hyde supported with $0.1 \mathrm{M}$ cacodylate [pH 7.2] for two hrs. The examples washed multiple times with a similar support and post-fixed in phosphatecushioned $1 \%$ osmium tetroxide for two hrs at room temperature at that point got dried out in rising evaluations of ethanol. After submersion in propylene oxide, examples inserted in epoxy gum blend. Semithin segments [1 um thick] were gotten and recolored with $1 \%$ tolu-idine blue and analyzed by light magnifying lens. Ultrathin areas [80-90 nm] were cut by LKB ultratome and recolored with uranyl acetic acid derivation and lead citrate. The ultrastructural examination was finished with a transmission electron magnifying instrument [ TEM ] at Tanta University.

\subsection{Statistical examination}

The information had recorded, put in tables at that point broke down utilizing SPSS [Statistical bundle for social science] rendition 20. Information were introduced as mean and standard deviation for quantitative information, recurrence, and dissemination for subjective information. They were tried utilizing ANOVA test $[\mathrm{F}$ value] Used to look at mean of multiple gatherings of quantitative information with utilizing post hoc test [ LSD] for between bunch examination, Paired t test for correlation between 2 ward implies for parametric information. The acknowledged degree of importance in this work was begun at $0.05[\mathrm{P}<0.05$ was considered significant] [30].

\section{Results \\ The final body weight and relative weight of testis:}

As regarding final body weight values after the end of the experiment, there was no significant difference between control groups, ascorbic acid treated group and curcumin treated group, while meloxicam treated group showed a highly significantly decrease in the final body weight, which greatly improved by increase in body weight in both curcumin \& meloxicam group and ascorbic acid \& meloxicam group, while there was no significant difference between curcumin \& meloxicam group and ascorbic acid \& meloxicam treated group Table (1). There was no significant difference between all studied groups regarding the relative weight of testis Table (2).

Table (1) Comparison between all groups regarding final body weight.

\begin{tabular}{|c|c|c|c|}
\hline Groups & Final body weight $[\mathrm{g}]$ & F test & P value \\
\hline Group [A]: $1^{\text {st }}$ Control group & $325.2 \pm 7.421$ & & \\
\hline Group $[B]: 2^{\text {nd }}$ Control group & $328.8 \pm 8.829$ & & \\
\hline Group [C]: Curcumin treated & $327.6 \pm 10.511$ & & \\
\hline Group [D]: Vitamin C treated & $331.8 \pm 9.931$ & 22.65 & $0 * *$ \\
\hline Group $[E]:$ Meloxicam treated & $294.1 \pm 5.82 \$$ @\# & & \\
\hline Group [F]: Meloxicam and curcumin treated & $310.4 \pm 10.637 €$ & & \\
\hline Group [G]: Meloxicam and vitamin C treated & $312.4 \pm 9.046^{\wedge}$ & & \\
\hline
\end{tabular}

- All values were expressed as mean \pm SD

- Number of rats in each group $=10$

- \$: indicate significant change as compared with group [A]

- @: indicate significant change as compared with group [C]
-\#: indicate significant change as compared with group [D]

- $€$ :indicate significant change as compared with group [E]

- ^:indicate significant change as compared with group $[\mathrm{E}]$

- $[<0.05]$ significant $[*] \&[<0.01]$ highly significant $[* *]$ 
Table (2) Comparison between all groups regarding relative weight [RW\%] of the testis.

\begin{tabular}{|c|c|c|c|}
\hline Groups & [ RW\%] & F test & P value \\
\hline Group [A]: $1^{\text {st }}$ Control group & $0.5 \pm 0.035$ & & \\
\hline Group $[B]: 2^{\text {nd }}$ Control group & $0.5 \pm 0.026$ & & \\
\hline Group $[C]:$ Curcumin treated & $0.49 \pm 0.033$ & & \\
\hline Group [D]: Vitamin C treated & $0.49 \pm 0.024$ & 1.116 & 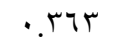 \\
\hline Group $[E]:$ Meloxicam treated & $0.48 \pm 015$ & & \\
\hline Group [F]: Meloxicam and curcumin treated & $0.5 \pm 0.033$ & & \\
\hline Group [G]: Meloxicam and vitamin $C$ treated & $0.49 \pm 0.029$ & & \\
\hline
\end{tabular}

- $\quad$ All values are expressed as mean $\pm \mathrm{SD}$

- Number of rats in each group $=10 \&[<0.05]$ significant $[*] \&[<0.01]$ highly significant [**]

\section{Sperm parameters}

\section{Total sperm count}

As regarding total sperm count values, there was no significant difference between control groups, ascorbic acid treated group and curcumin treated group, while meloxicam treated group showed a highly significantly decrease in total sperm count, while total sperm count showed high significant increase in both protective groups [curcumin \& meloxicam group and ascorbic acid \& meloxicam group], while there was no significant difference between two protective groups Table (3).

Table (3) Comparison between all groups regarding total sperm count.

\begin{tabular}{|c|c|c|c|}
\hline Groups & Total sperm count $\left[\times 10^{6}\right]$ & F test & P value \\
\hline Group [A]: $1^{\text {st }}$ Control group & $46.5 \pm 9.56$ & \multirow{7}{*}{$1 \leq . Y Y O$} & \multirow{7}{*}{$* *$. } \\
\hline Group $[B]: 2^{\text {nd }}$ Control group & $43.36 \pm 7.71$ & & \\
\hline Group [C]: Curcumin treated & $49.82 \pm 11.91$ & & \\
\hline Group [D]: Vitamin C treated & $47.98 \pm 10.29$ & & \\
\hline Group [E]: Meloxicam treated & $21.69 \pm 2.08 \$ @ \#$ & & \\
\hline Group [F]: Meloxicam and curcumin treated & $41.08 \pm 5.22 €$ & & \\
\hline Group [G]: Meloxicam and vitamin C treated & $\pm 3.62^{\wedge} \quad r . \cdot v$ & & \\
\hline
\end{tabular}

- All values were expressed as mean \pm SD

- Number of rats in each group $=10$

- \$:indicate significant change ascompared with group [A]

- @: indicate significant change as compared with group [C]

- \#: indicate significant change as compared with group [D]

- $€$ :indicate significant change as compared with group [E]

- ^ :indicate significant change as compared with group [E]

- $[<0.05]$ significant $[*] \&[<0.01]$ highly significant $[* *]$

\section{Sperm motility}

As regarding The percentage [\%] sperm motility, there was no significant difference between control groups, ascorbic acid treated group and curcumin treated group, while meloxicam treated group showed a highly significantly decrease the percentage sperm motility, while the percentage sperm motility showed high significant increase in both protective groups [curcumin \& meloxicam group and ascorbic acid \& meloxicam group], while there was no significant difference between two protective groups Table (4).

Table (4) Comparison between all groups regarding sperm motility.

\begin{tabular}{|c|c|c|c|}
\hline Groups & Sperm motility [\%] & F test & P value \\
\hline Group [A]: $1^{\text {st }}$ Control group & $76.9 \pm 19.94$ & & \\
\hline Group [B]: $2^{\text {nd }}$ Control group & $75.3 \pm 17.6$ & & \\
\hline Group $[\mathrm{C}]$ : Curcumin treated & $79.5 \pm 15.71$ & & \\
\hline Group [D]: Vitamin C treated & $74.5 \pm 17.39$ & 11.459 & $0 * *$ \\
\hline Group [E]: Meloxicam treated & $31 \pm 18.52 \$$ @\# & & \\
\hline Group [F]: Meloxicam and curcumin treated & $69 \pm 7.38 €$ & & \\
\hline Group [G]: Meloxicam and vitamin C treated & $58 \pm 11.59^{\wedge}$ & & \\
\hline
\end{tabular}


- All values were expressed as mean \pm SD

- Number of rats in each group $=10$

- \$: indicate significant change as compared with group [A]

- @: indicate significant change as compared with group [C]

- \#: indicate significant change as compared with group [D]

- $€$ :indicate significant change as compared with group $[\mathrm{E}]$

- ^ :indicate significant change as compared with group [E]

- [<0.05] significant[*] \& [<0.01] highly significant[**]
Biochemical results

1-Testosterone hormone level

The results showed that no significant difference was founded in the testosterone level between control groups, ascorbic acid treated group and curcumin treated group, while there was a non considerable decrease in mean testosterone level in the meloxicam-treated group, while concomitant use of curcumin or ascorbic acid with meloxicam in protective groups resulted in an increase in mean testosterone level but this rise was insignificant, while there was no significant difference between two protective groups Table (5).

Table (5) Comparison between all groups regarding testosterone level.

\begin{tabular}{lccc}
\hline Groups & Testosterone level [ng/ml] & F test & P value \\
\hline Group [A]: 1 & $2.635 \pm 1.0625$ & & \\
Group [B]: 2 $2^{\text {st }}$ Control group & $2.565 \pm 1.0485$ & & \\
Group [C]: Curcumin treated & $2.714 \pm 1.0877$ & & \\
Group [D]: Vitamin C treated & $2.689 \pm 1.0544$ & 0.946 & 0.469 \\
Group [E]: Meloxicam treated & $1.775 \pm 1.1023$ & & \\
Group [F]: Meloxicam and curcumin treated & $2.485 \pm 1.1161$ & & \\
Group [G]: Meloxicam and vitamin C treated & $2.315 \pm 1.0133$ & & \\
\hline
\end{tabular}

$$
\begin{gathered}
\text { - All values were expressed as mean } \pm \text { SD } \\
\bullet \text { Number of rats in each group }=10 \\
\text { - }[<0.05] \text { significant }[*] \&[<0.01] \text { highly significant }[* *]
\end{gathered}
$$

\section{Oxidative stress parameters result}

\section{Glutathione [GSH] level}

There was highly significant rise in GSH level in ascorbic acid treated group and curcumin treated group as compared to control groups, while meloxicam treated group showed a highly significantly decrease in GSH level. GSH level showed high significant increase in curcumin \& meloxicam group and significant increase in ascorbic acid \& meloxicam group, while the difference between two protective groups was significant Table (6).

Table (6) Comparison between all groups regarding glutathione [GSH] level.

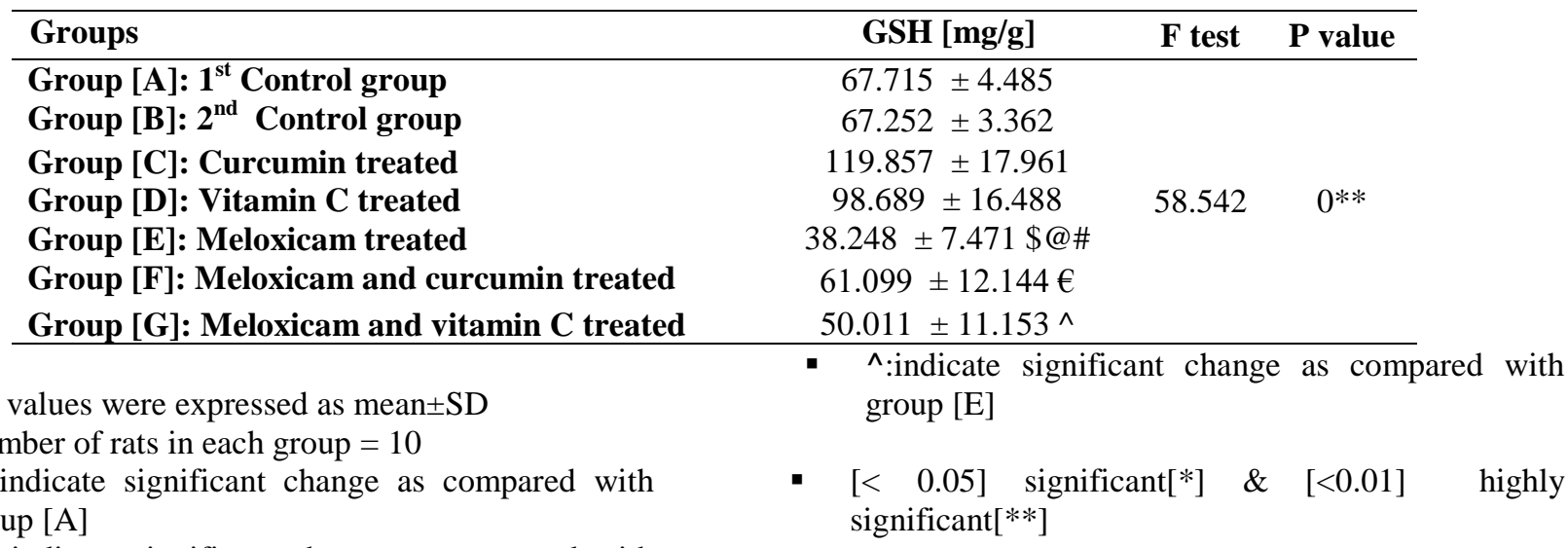

- All values were expressed as mean $\pm \mathrm{SD}$

- Number of rats in each group $=10$

- \$: indicate significant change as compared with group $[\mathrm{A}]$

- @: indicate significant change as compared with group [C]

- \#: indicate significant change as compared with group [D]

- $€$ :indicate significant change as compared with group [E]

\section{Superoxide dismutase [SOD] level}

There was highly significant rise in SOD level in ascorbic acid treated group and curcumin treated group as compared to control groups, while meloxicam treated group showed a highly significantly decrease in SOD level. SOD level showed high significant increase in both 
protective groups [curcumin \& meloxicam group and ascorbic acid \& meloxicam group], while the difference between two protective groups was high significant Table (7).

Table (7) Comparison between all groups regarding superoxide dismutase [SOD] level.

\begin{tabular}{|c|c|c|c|}
\hline Groups & SOD [U/g] & F test & P value \\
\hline Group [A]: $1^{\text {st }}$ Control group & $100.772 \pm 12.701$ & \multirow{7}{*}{99.874} & \multirow{7}{*}{$0 * *$} \\
\hline Group [B]: $2^{\text {nd }}$ Control group & $101.277 \pm 10.952$ & & \\
\hline Group $[C]$ : Curcumin treated & $171.575 \pm 9.090$ & & \\
\hline Group [D]: Vitamin C treated & $131.768 \pm 14.397$ & & \\
\hline Group [E]: Meloxicam treated & $51.684 \pm 9.715$ \$@\# & & \\
\hline Group [F]: Meloxicam and curcumin treated & $89.782 \pm 13.601 €$ & & \\
\hline Group [G]: Meloxicam and vitamin $C$ treated & $73.967 \pm 14.929^{\wedge}$ & & \\
\hline
\end{tabular}

- All values were expressed as mean $\pm \mathrm{SD}$

- Number of rats in each group $=10$

- \$: indicate significant change as compared with group [A]

- @: indicate significant change as compared with group [C]

- \#: indicate significant change as compared with group [D]

- $€$ :indicate significant change as compared with group [E]

- $\wedge$ :indicate significant change as compared with group [E]
- $[<0.05]$ significant[*] \& $[<0.01] \quad$ highly significant $[* *]$

\section{Glutathione peroxidase [GPx] level:}

There was highly significant rise in GPx level in ascorbic acid treated group and curcumin treated group as compared to control groups, while meloxicam treated group showed a highly significantly decrease in GPx level. GPx level showed high significant increase in both protective groups [curcumin \& meloxicam group and ascorbic acid \& meloxicam group], while the difference between two protective groups was high significant Table (8).

Table (8) Comparison between all groups regarding glutathione peroxidase [GPx] level.

\begin{tabular}{|c|c|c|c|}
\hline Groups & GPx [U/g] & F test & P value \\
\hline Group [A]: $\mathbf{1}^{\text {st }}$ Control group & $8461.355 \pm 704.404$ & & \\
\hline Group [B]: $2^{\text {nd }}$ Control group & $8446.444 \pm 659.5961$ & & \\
\hline Group [C]: Curcumin treated & $12842.575 \pm 940.847$ & & \\
\hline Group [D]: Vitamin C treated & $10977.242 \pm 1098.35$ & 42.19 & $0 * *$ \\
\hline Group [E]: Meloxicam treated & $5704.326 \pm 1397.72$ \$@\# & & \\
\hline Group [F]: Meloxicam and curcumin treated & $10563.037 \pm 1052.41 €$ & & \\
\hline Group [G]: Meloxicam and vitamin $C$ treated & $7684.198 \pm 1814.19^{\wedge}$ & & \\
\hline
\end{tabular}

- All values were expressed as mean \pm SD

- Number of rats in each group $=10$

- \$: indicate significant change as compared with group [A]

- @: indicate significant change as compared with group [C]

- \#: indicate significant change as compared with group [D]

- $€$ :indicate significant change as compared with group [E]

- $\wedge$ :indicate significant change as compared with group [E]
- $[<0.05]$ significant[*] \& [<0.01] highly significant[**]

\section{Malondialdehyde [MDA] level.}

There was highly significant decrease in curcumin treated group and non-significant decrease in ascorbic acid treated group as compared to control groups, while meloxicam treated group showed a highly significantly rise in MDA level. MDA level showed high significant decrease in both protective groups [curcumin \& meloxicam group and ascorbic acid \& meloxicam group], while the difference between two protective groups was non significant Table (9).

Table(9) Comparison between all groups regarding malondialdehyde [MDA] level.

\begin{tabular}{lcc}
\hline Groups & MDA [nmol/g] & F test \\
\hline Group [A]: $\mathbf{1}^{\text {st }}$ Control group & $1153.547 \pm 222.339$ & \\
Group [B]: $2^{\text {nd }}$ Control group & $1211.75 \pm 254.263$ & 48.071 \\
Group [C]: Curcumin treated & $856.95 \pm 244.678$ & $0 * *$
\end{tabular}


Table (9) Continue

\begin{tabular}{lc} 
Group [D]: Vitamin C treated & $1023.799 \pm 232.736$ \\
Group [E]: Meloxicam treated & $2566.038 \pm 291.743 \$ @ \#$ \\
Group [F]: Meloxicam and curcumin treated & $1126.481 \pm 248.837 €$ \\
Group [G]: Meloxicam and vitamin C treated & $1278.116 \pm 306.689^{\wedge}$ \\
\hline
\end{tabular}

- All values were expressed as mean $\pm \mathrm{SD}$

- Number of rats in each group $=10$

- \$: indicate significant change as compared with group [A]

- @: indicate significant change as compared with group [C]

- \#: indicate significant change as compared with group [D]

- $€$ :indicate significant change as compared with group [E]

- $\quad$ :indicate significant change as compared with group [E]

- $\quad[<0.05]$ significant[*] \& $[<0.01] \quad$ highly significant $[* *]$
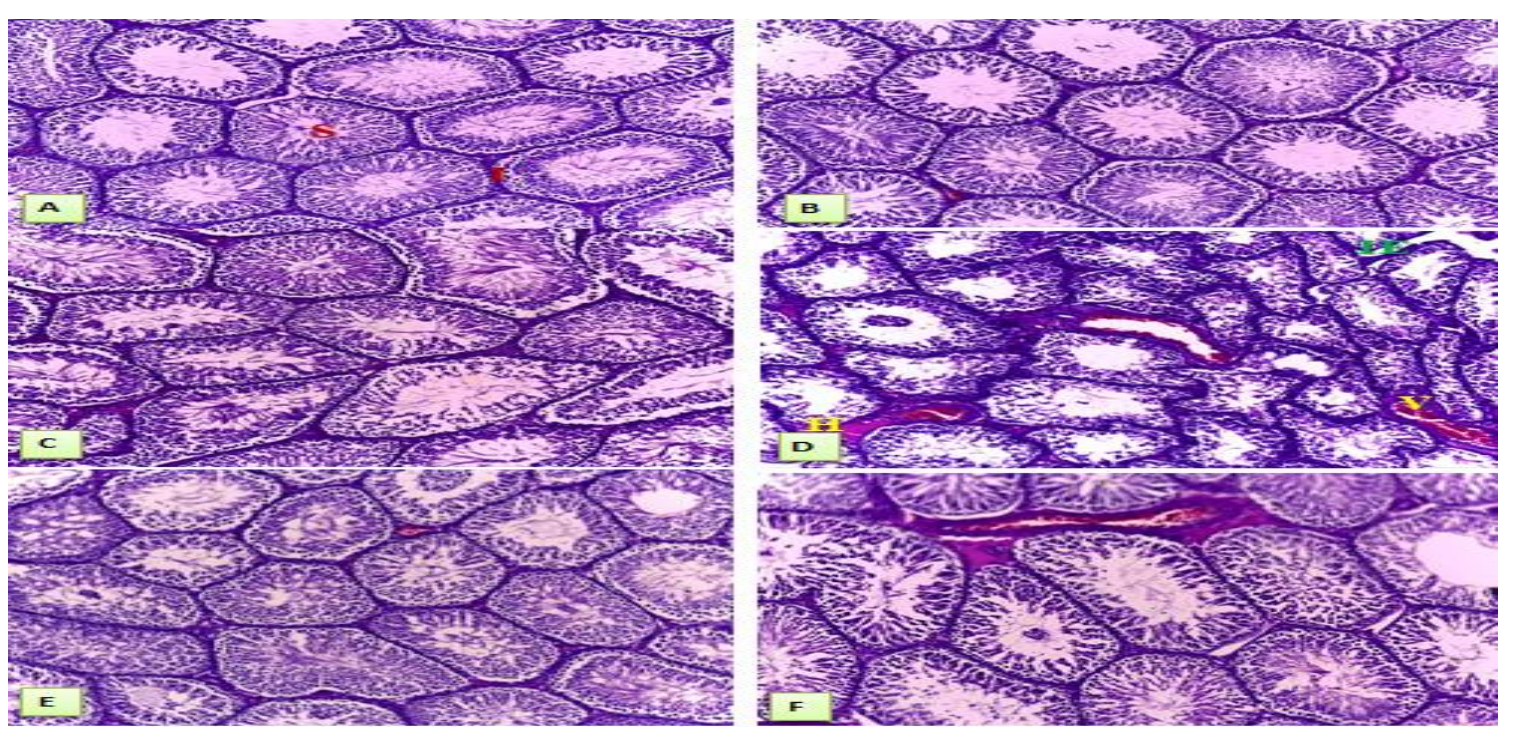

Fig (1)Comparison between all groups regarding histopathological changes.
A: Photomicrograph of a section in rat's testis prepared from a control rat showing normal architecture with well arranged closely matted seminefrous [S] tubule

B: Photomicrograph of a section in rat's testis prepared from curcumin treated group showing normal architecture with well arranged closely matted seminefrous tubule [S] and normal interstitial tissues [I] [Hx \& Ex 100].

C: Photomicrograph of a section in rat's testis prepared from ascorbic acid treated group showing normal architecture with well arranged closely matted seminefrous tubule [S] and normal interstitial tissues [I] [Hx \& E x 100].

D: A photomicrograph of a section in rat's testis prepared from meloxicam- treated rat showing distortion of the architecture of seminiferous tubules [S] with tubular degeneration and interstitium showed deposition and normal interstitial [I] tissues [Hx \& E x 100].

\section{Histopathological finding \\ Light microscope results}

The control groups, curcumin treated group and ascorbic acid treated group preserved architecture with well arranged seminiferous tubules, histopathological changes in meloxicam-treated rats were representing in prominent interstitial congested blood vessels, edema, fibrosis like appearance and deposition of hyaline material, distortion of the architecture of seminiferous tubules with hypocellularity of all stages with decreased numbers and sometimes absent of spermatids and mature sperms, tubular degeneration and intercellular vaculaization. These changes were improved in both protective groups [curcumin \& meloxicam group and ascorbic acid \& meloxicam group] Figs $(1,2)$. of hyaline $[\mathrm{H}]$ material, congested blood vessels $[\mathrm{V}]$ and interstitial edema [IE] [H\&E x 100]

E: A photomicrograph of a section in rat's testis prepared from meloxicam and curcumin group showed normal architecture of seminefrous tubules with minimal interstitial fibrosis and less congested blood vessels [V] [H\&E x 100].

F: A photomicrograph of a section in rat's testis prepared from meloxicam and ascorbic acid group showed normal architecture of seminefrous tubules with some interstitial hyaline deposition, congested blood vessels [V] and interstitial edema [IE] [H\&E x 100].

\section{Group and meloxicam \& ascorbic acid group] regarding histopathological changes}

A: A photomicrograph of a section in rat's testis prepared from meloxicam- treated rat showing degeneration of spermatogonia $[\mathrm{SG}]$ and decreased 
spermatogenesis with intercullar vaccuoles $[\mathrm{Vc}][\mathrm{H} \& \mathrm{E} \mathrm{x}$ 400].

B: A photomicrograph of a section in rat's testis prepared from meloxicam- treated rat showing interstitial edema with congested blood vessel [V], fibrosis [F] like appearance of interstitium and hyaline $[\mathrm{H}]$ deposition [H\&E x 400].

C: A photomicrograph of a section in rat's testis prepared from meloxicam \& curcumin treated rat showing normal architecture of seminefrous tubules [S] with normal spermatogenic cells and ongoing spermatogenesis and minimal vascular congestion and fibrosis like appearance of interstitial [I] tissue [H\&E x 400].

D: A photomicrograph of a section in rat's testis prepared from meloxicam and ascorbic acid treated group showed near normal architecture of seminefrous tubules with normal sertoli cell, spermatocyte and spermatid, while some semineferous tubules showed intercellular vacuoles [Vc] with deposition of hyaline material in interstitial tissue and some congested blood vessels [H\&E x 400].
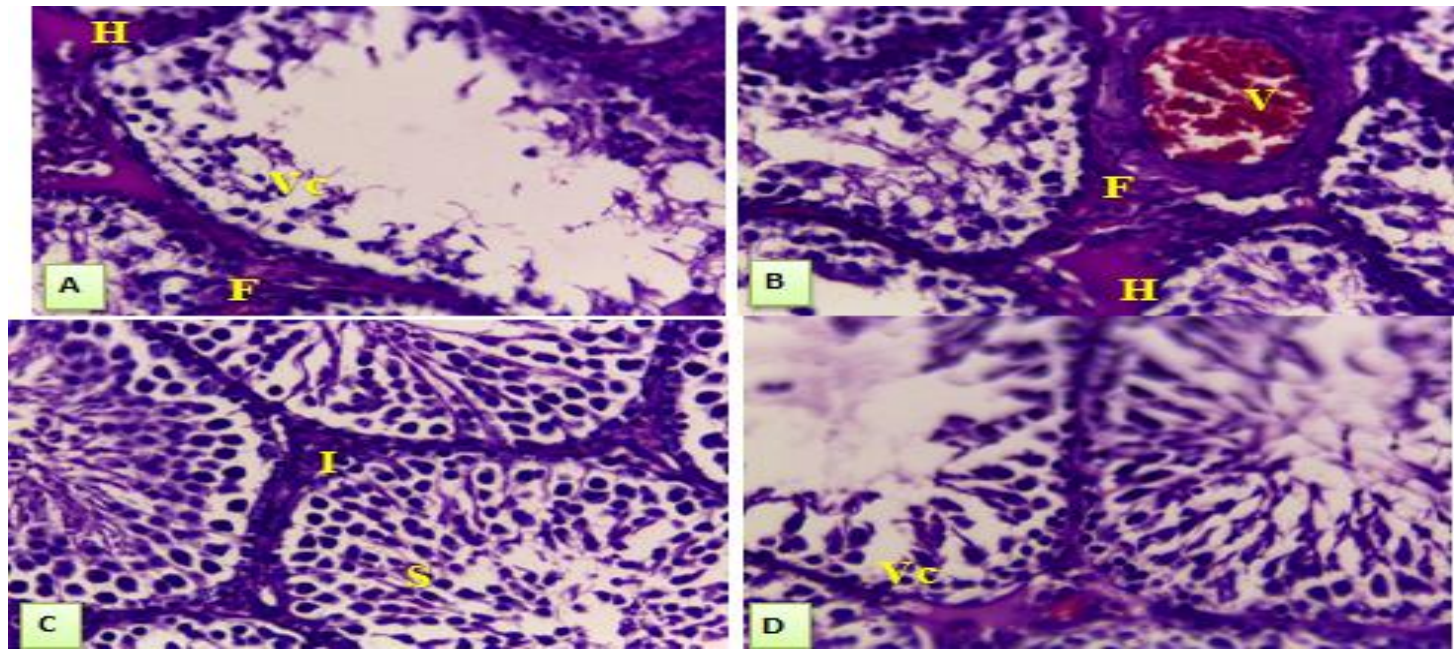

Fig (2) Comparison between meloxicam group and protected groups [meloxicam \& curcumin.

\section{Electron microscope results}

The control groups, curcumin treated group and ascorbic acid treated group showed normal histological finding while meloxicam treated group showed many abnormalities representing in thickening of basement membrane, swollen mitochondria with appearance of autophagic vacuoles within sertoli cells, spermatogonia with perinuclear spaces and swollen vacuolated mitochondia, spermatocyte with cytoplasmic vacuolation $\&$ perinuclear spaces and swollen vacuolated mitochondia and degenerated spermatid with distorted acrosomal cap, electron dense bodies and swollen vacuolated mitochondia, while sperms showed dissaranged flagellar component in cross section and leidyg cells showed cytoplasmic vacuolation. These changes were improved in both protected groups [curcumin \& meloxicam group and ascorbic acid \& meloxicam group] Figs (3-14).

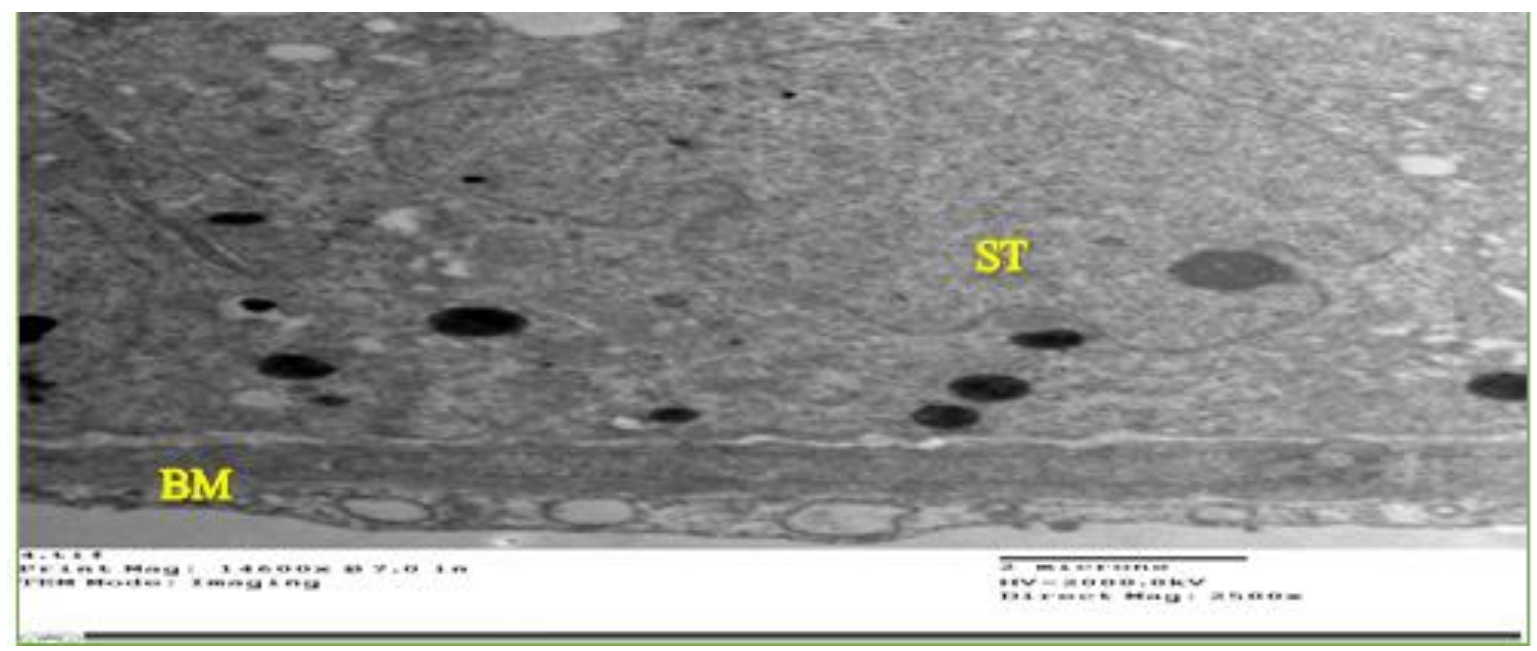

Fig (3) An electron micrograph of a section from the testis of the control rat showing normal basement membrane [BM] \& sertoli cells [ST] [OM X 1500] 


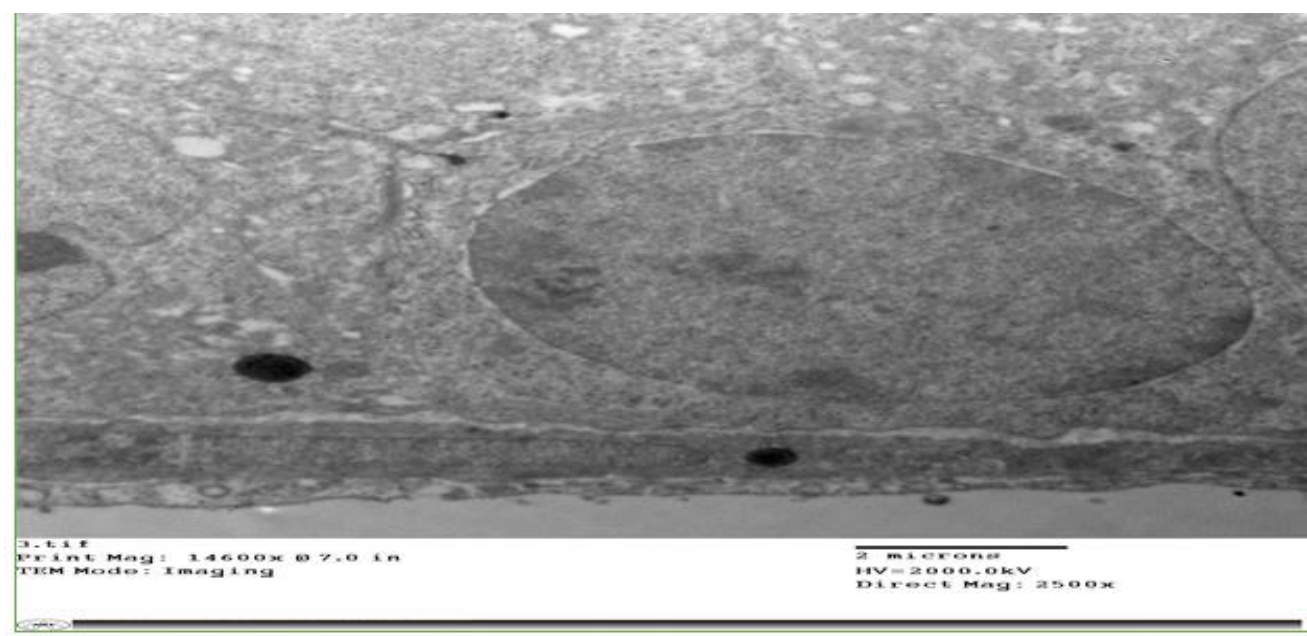

Fig (4) An electron micrograph of a section from the testis of the control rat showing normal basement membrane [BM] \& spermatogonium [SG] [OM X 1500].

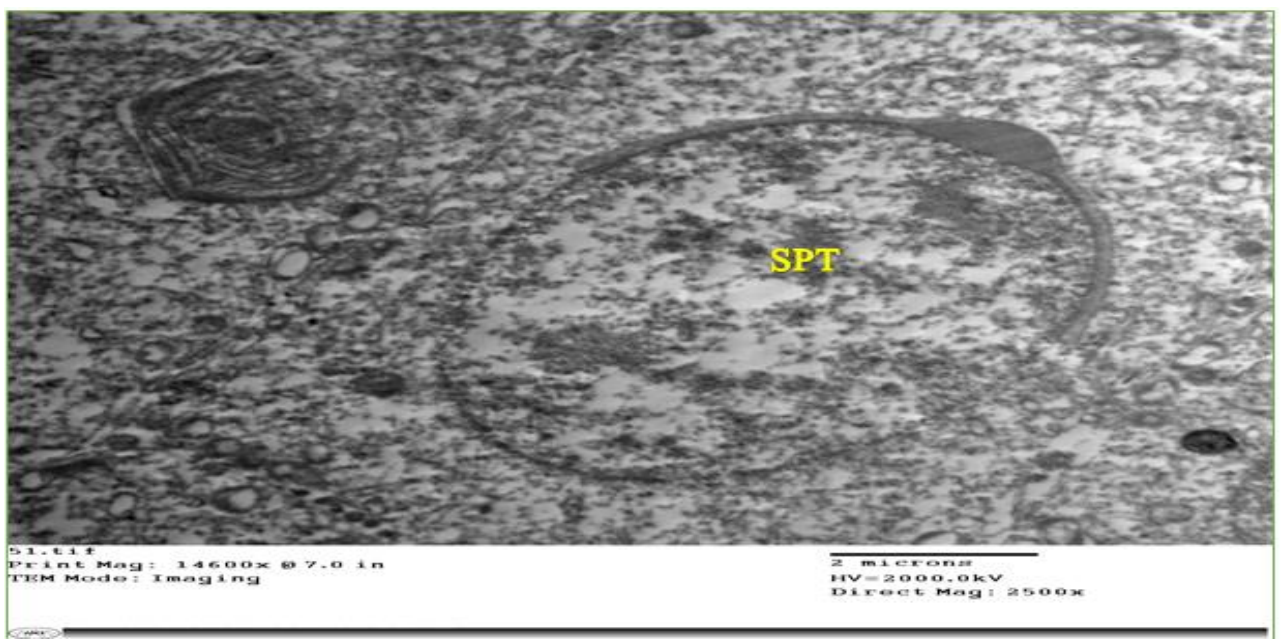

Fig (5) An electron micrograph of a section from the testis of the control rat showing normal spermatid [SPT] [OM X 1500].

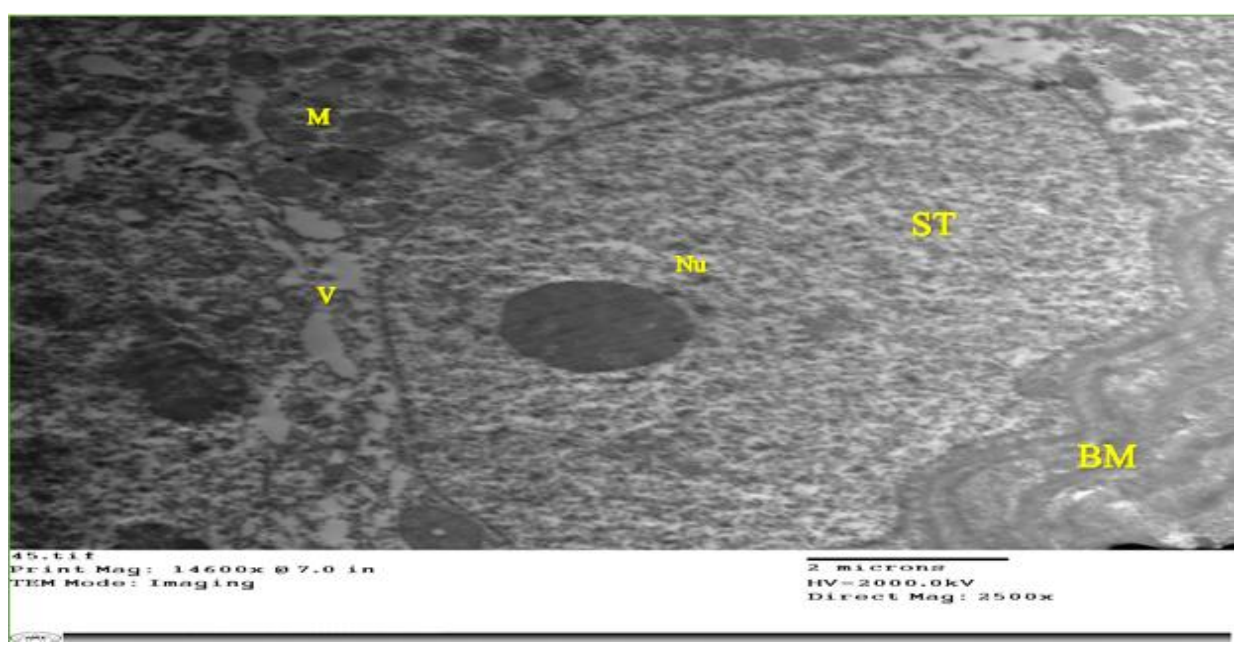

Fig (6) An electron micrograph of a section in testis of the meloxicam treated group showing Sertoli cell [ST] having a large indented nucleus with a prominent nucleolus [Nu], swollen mitochondria $[\mathrm{M}]$, with cytoplasmic vaculation [V] lying on a thick wavy basement membrane [BM] [OM X 2500]. 


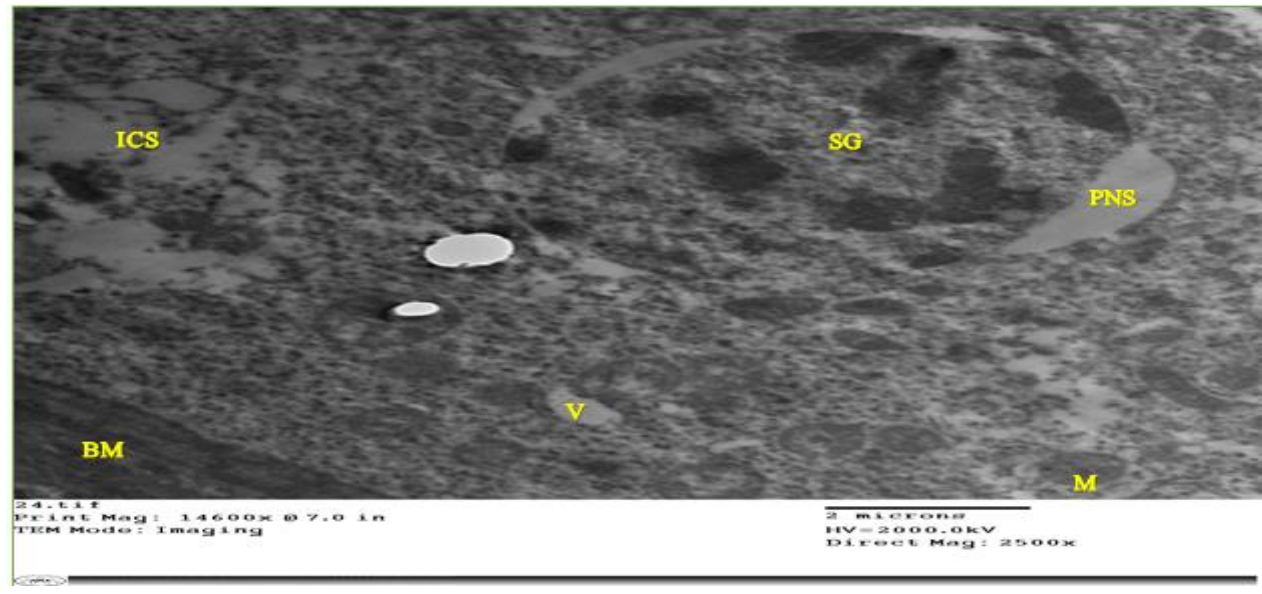

Fig (7) An electron micrograph of a section in testis of the meloxicam treated group showing spermatogonium cell [SG] with apoptotic features as condensation of nuclear material [arrow head], perinuclear space [PNS], cytoplasm vacuoles [V], swollen vacuolated mitochondria [M] and intercellular spaces [ICS] lying on a thick basement membrane [BM] [OM X 2500].

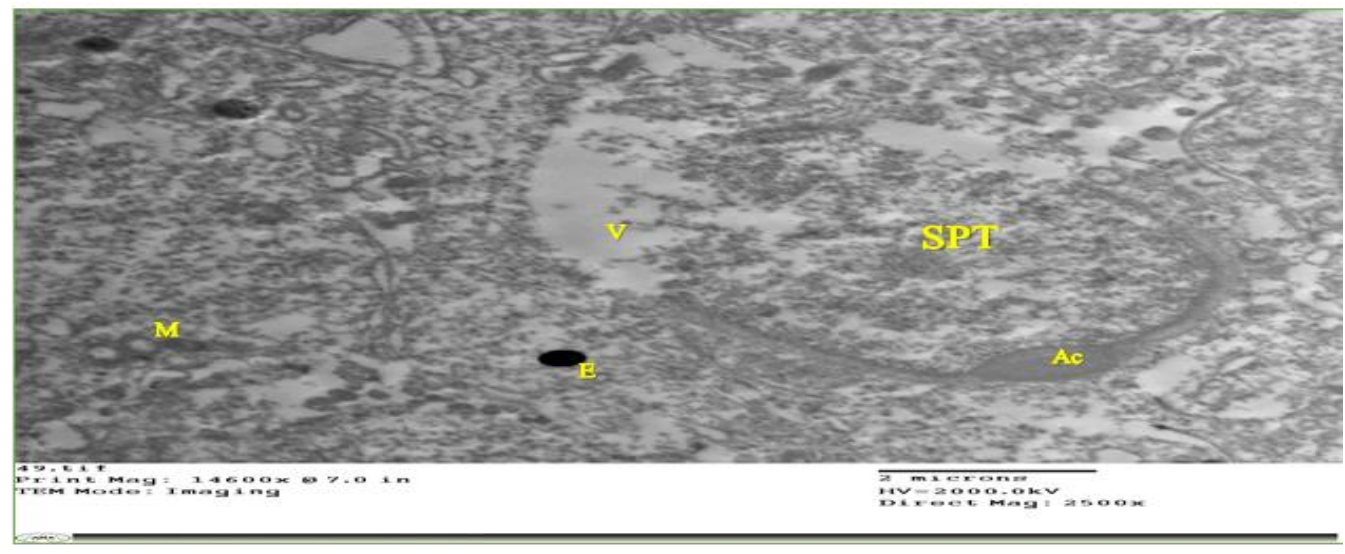

Fig (8) An electron micrograph of a section in testis of the meloxicam treated group showing spermatid [SPT] with distorted acrosomal cap,vaculated [V] cytoplasm, appearance of electron dense bodies [E] and swollen vacuolated mitochondria [M] [OM X 2500].

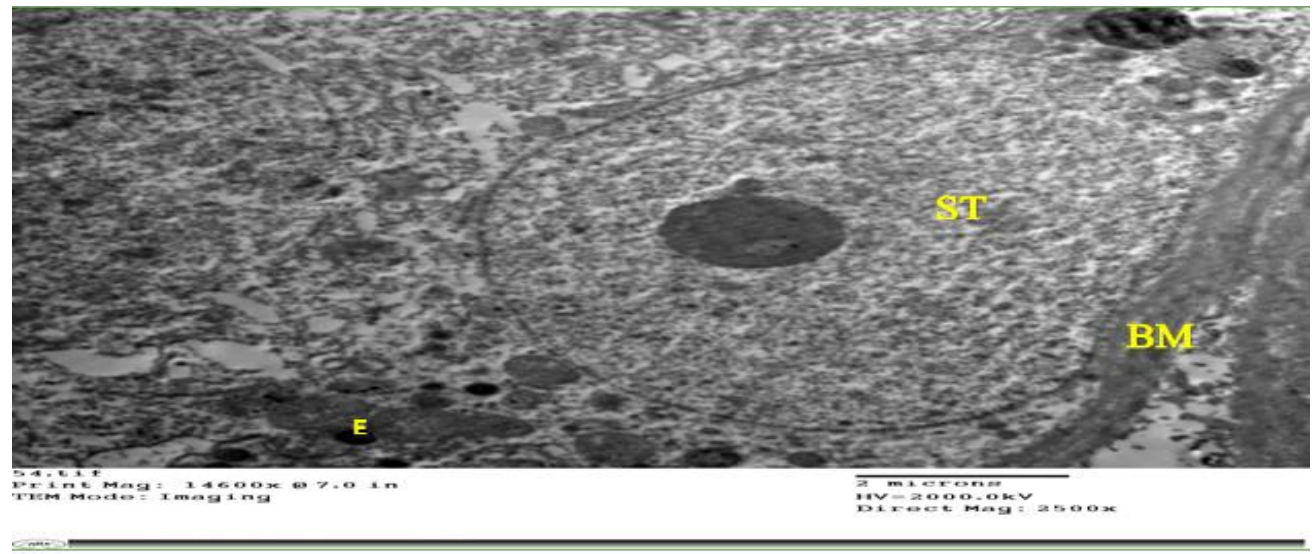

Fig (9) An electron micrograph of a section in testis of the meloxicam and curcumin treated group showing Sertoli cell [ST] with a large indented nucleus, electron-dense bodies [E], with marked decrease in the number of cytoplasmic vacuoles [V], decreased mitochondrial $[\mathrm{M}]$ swelling and near normal basement membrane [BM] [OM X 2500]. 


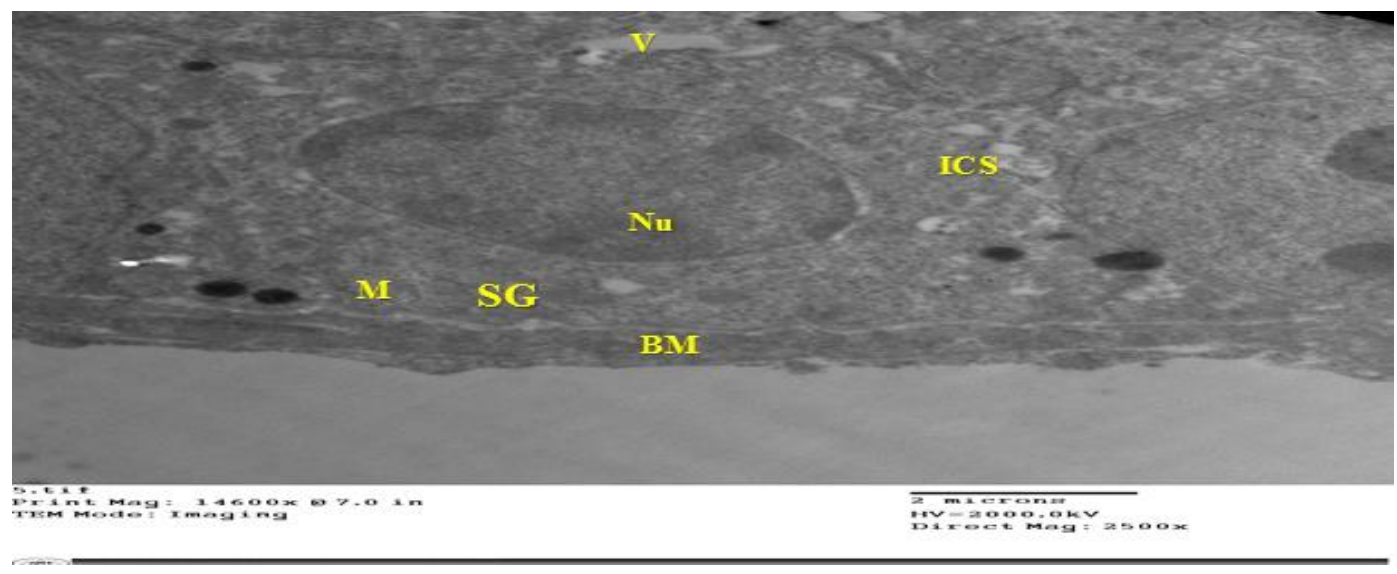

Fig (10) An electron micrograph of a section in testis of the meloxicam and curcumin treated group showing spermatogonium cell [SG] with marked decrease in apopototic changes as normal nucleus $[\mathrm{Nu}]$, marked decrease in the number of cytoplasmic vacuoles [V], decreased intercellular spaces [ICS] decreased mitochondrial [M] swelling and near normal basement membrane [BM] [OM X 2500].

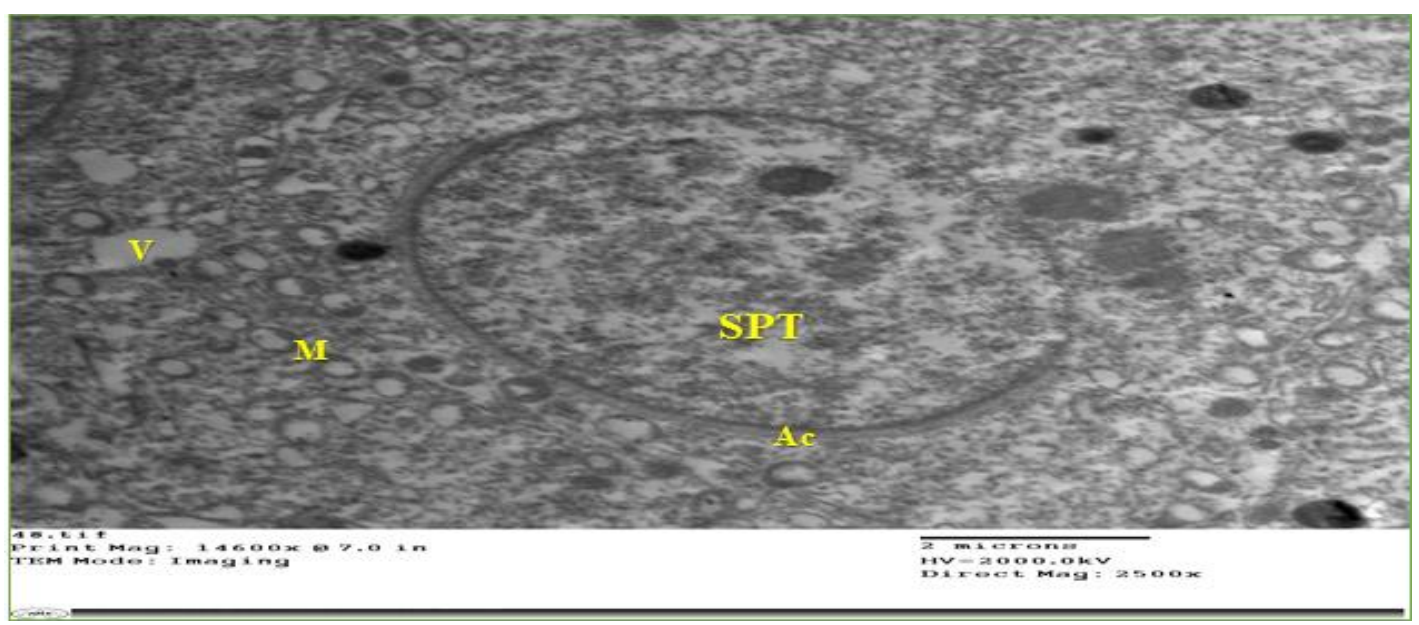

Fig (11) An electron micrograph of a section in testis of the meloxicam and curcumin treated group showing spermatid [SPT] with well-developed acrosomal cap [Ac] with marked decrease in cytoplasmic vacuoles and near normal mitochondrial [M] appearance [OM X 2500].

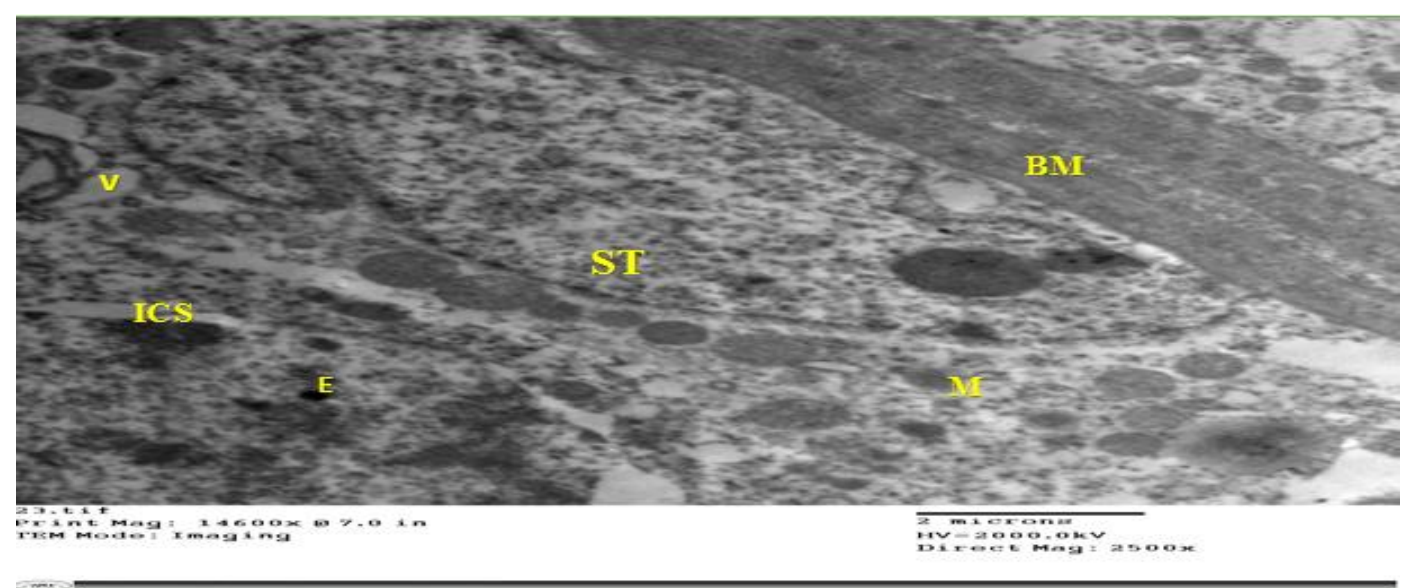

Fig (12) An electron micrograph of a section in testis of the meloxicam and vitamin $\mathrm{C}$ treated group showing Sertoli cell [ST] with a large indented nucleus, electron-dense bodies [E], with less decrease in the number of cytoplasmic vacuoles, few intercellular spaces [ICS], less decreased mitochondrial swelling and thick basement membrane [BM] [OM X 2500]. 


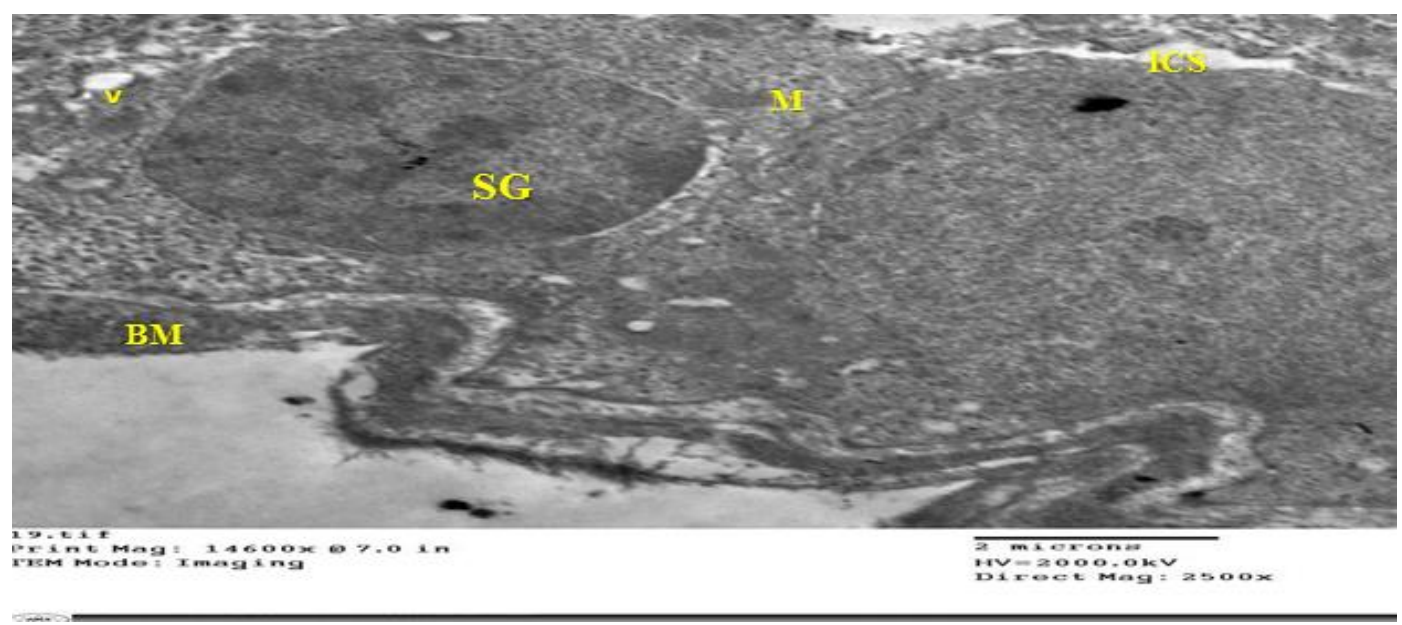

Fig (13) An electron micrograph of a section in testis of the meloxicam and vitamin $C$ treated group showing Spermatogonium cell [SG] with less decrease in the number of cytoplasmic vacuoles [V], few intercellular spaces [ICS], less decreased mitochondrial [M] swelling and wavy basement membrane [BM] [OM X 2500].

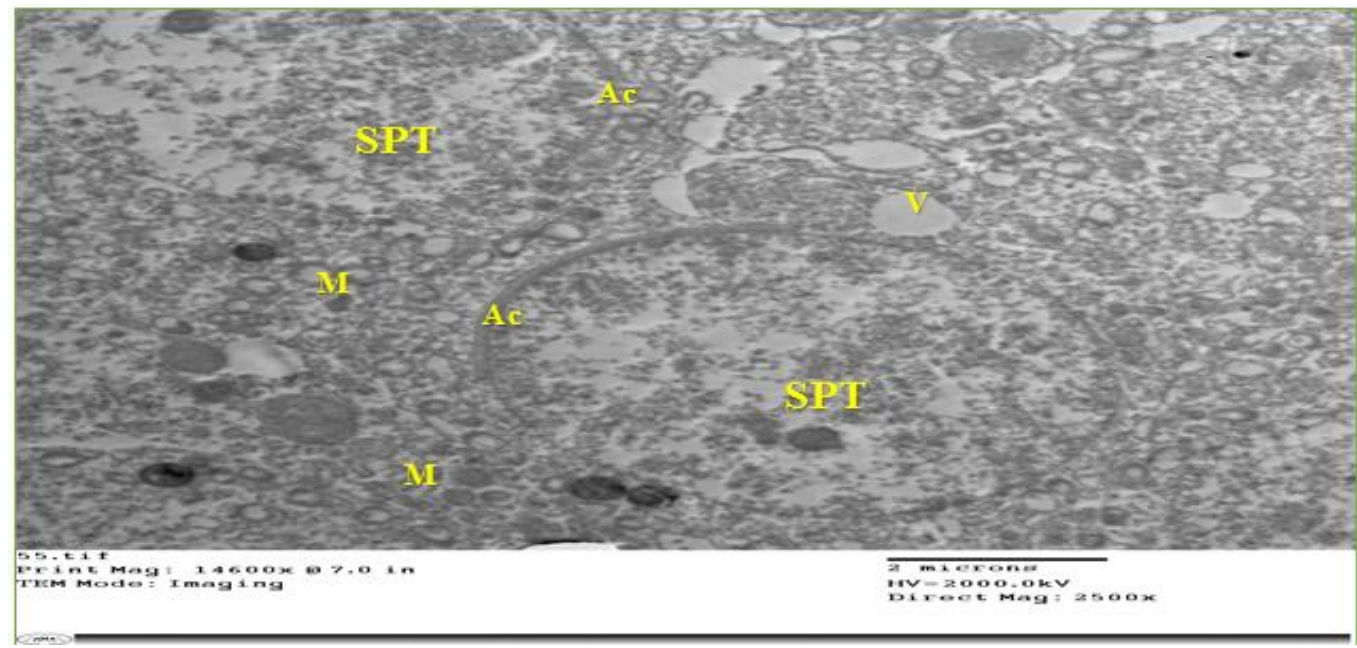

Fig [14] An electron micrograph of a section in testis of the meloxicam and vitamin $C$ treated group showing two spermatids [SPT] the lower one with well-developed acrosomal cap $[\mathrm{Ac}]$ with decreased cytoplasmic vacuoles $[\mathrm{V}]$ and near normal mitochondria $[\mathrm{M}]$ while the upper shows degeneration with distorted acrosomal cap [Ac] with less decreased cytoplasmic vacuoles and some mitochondrial swelling [OM X 2500].

\section{Discussion}

Non-steroidal mitigating drugs [NSAIDs] are the most generally utilized gathering of medications today. These medications are habitually favored for conditions, for example, cerebral pain, joint pain, and essential dysmenorrhea particularly because of their pain relieving and calming impacts, while its drawn out utilize was confined by the way that these medications were demonstrated to potentially cause antagonistic impacts restricting the drawn out organization of these medications to certain patients, for example, gastrointestinal, hepatic and renal unfriendly impacts [18] and $[60]$.

It is notable that constant organization of high dosages of NSAIDs, for example, paracetamol and phenacetin to the male rodents lead to testicular decay and hindrance of spermatogenesis. The specific component of the interminable impact of these medications on testis isn't completely seen particularly past examinations inspecting the impacts of prostaglandins and prostaglandin union inhibitors on male ripeness and spermatogenesis have uncovered clashing outcomes [69].

Nutrient $\mathrm{C}$ is viewed as a significant cancer prevention agent in the testis. It kills ROS and forestalls sperm agglutination. It is a benefactor of electrons for redox frameworks, forestalls lipid peroxidation, reuses nutrient $\mathrm{E}$ and secures against DNA harm actuated by hydrogen peroxide radical [31].

Past examinations have additionally indicated that curcumin, which is dynamic part of turmeric [Curcuma Longa], has the ability of forestalling testicular oxidative worry by expanding the atomic movement of atomic 
factor erythroid 2-related factor 2 [Nrf-2], a record factor answerable for the initiation of the cancer prevention agent protection arrangement of the cell [58] and [78].

The current work tentatively concentrated on male grown-up pale skinned person rodents, expected to examine the ceaseless poisonous impacts of semi-specific COX-2 inhibitor, meloxicam, on the testis and the function of oxidative worry in pathogenesis and to assess the possible defensive part of cell reinforcements, curcumin and nutrient $\mathrm{C}$ each alone against this poisonousness through considering changes in the body and the testis loads, testosterone hormone level, sperm boundaries, oxidative pressure boundaries, histopathology and ultrastructure of testicular tissue.

Concerning weight, weight put on change and testis weight, our outcomes demonstrated that meloxicam organization brought about an exceptionally noteworthy abatement in the body weight, weight put on and testis weight when contrasted with control gatherings, curcumin treated gathering and nutrient $\mathrm{C}$ treated gathering, simultaneously attending organization of meloxicam with curcumin or nutrient $\mathrm{C}$ brought about extraordinary improvement showed by a profoundly critical increment in body weight, decline in weight gain decrease and huge ascent in testis weight when contrasted with meloxicam treated gathering. While, there was no noteworthy distinction between curcumin with meloxicam treated gathering and nutrient $\mathrm{C}$ with meloxicam treated gathering. There was no huge distinction between completely considered gatherings with respect to the overall load of testis.

The aftereffect of past investigations who considered toxicopathological impacts of tentatively prompted meloxicam poisonousness in rodents match with our outcome as there was huge decrease in body weight and weight increase recorded in meloxicam treated gatherings in contrast and the benchmark groups. This impact was clarified by immediate or aberrant impact of on gastrointestinal lot coming about in as disintegrations in the gastric mucosa of the treated creatures brought about by to long haul organization of meloxicam causing diminished hunger and assimilation [70] and [15] and [36].

As to testis weight, the aftereffect of different examinations that researched the impact of meloxicam on some regenerative parts of male rodents agree with our outcomes, as the testis loads were of higher qualities in control bunches than the gatherings treated with meloxicam particularly two months of treatment and the distinction among bunches is measurably huge [28]\& [48].

The abatement in testis weight appears to be possible with the way that testosterone is liable for the development and improvement of male optional sex organs [28]\& [48]. While different investigations credited this impact to the immediate impact of medications on gonadal tissue [leydig cells] or its inhibitory consequences for nerve center pituitary-testis pivot [18] and [50 and [77].
The upgrading impact of curcumin on testicular weight was accounted for in past examinations that meant to assess the defensive of curcumin against testicular poison levels. Curcumin incited a noteworthy increment in the heaviness of mouse testis when utilized as a defensive operator against dexamethasone-prompted testicular harmfulness [41] and against titanium dioxide testicular poisonousness in [38] who is proposed that the job curcumin in upgrading testicular loads might be because of its capacity to forestall spermatogenesis imperfections and avoidance of germ cell demise in the seminiferous tubules expanding all phases of spermatogenic cells.

Nutrient $\mathrm{C}$ function in the avoidance of the diminished testis weight by harmful substances was clarified by its part as cofactor for hydroxylation of collagen [an significant segment of the extracellular matrix] as revealed by [46] and [10] moreover, nutrient $\mathrm{C}$ may improve gonads' loads optional to diminish the oxidative pressure improving spermatogenesis and testis cell mass [62].

Concerning tally and motility, our investigation demonstrated high huge reduction in sperm tally and motility following 63 days in meloxicam regarded bunch when contrasted with control gathering, curcumin treated gathering and nutrient $\mathrm{C}$ treated gathering, while in both defensive gatherings [meloxicam and curcumin and meloxicam and nutrient $\mathrm{C}$ ], there was high huge ascent in mean estimation of all out sperm check and motility, while there was no critical distinction between the two defensive gatherings.

These outcomes were in full concurrence with past works that meant to examine the effect of long haul organization of meloxicam on testis, meloxicam initiated a huge lessening in sperm cell tally, individual and mass motility toward the finish of the investigation just as a critical reduction in the percent of live/dead and expanded the percent of sperm variations from the norm. The diminished sperm tally shows unfavorable consequences for spermatogenesis in rodents controlled the tried medications debilitating sperm motility in these rodents demonstrating a deformity in support of motility [35] and [69] and [1] and [48]

The negative impact of rehashed meloxicam organization on sperm boundaries can be ascribed to the diminished prostaglandin levels brought about by the catalyst hindrance prompted by meloxicam [69]. PG-E and PG-F assume a key part in sperm improvement and their capacity likewise expands contractility of the epididymis tubule [29]. While Reduction in sperm elements may be a result of discouraged degrees of testosterone [73].

Meloxicam may apply its sperm poisonousness in rodents conceivably through its oxidative pressure components. This outcome is firmly upheld by [5]] study that clarified the hurtful impacts of an intense paracetamol overdose on sperm boundaries could be ascribed to the immediate results of lipid peroxidation and receptive oxygen species creation in the testicles, however not testosterone levels, which thus harm germ cells at various 
phases of advancement. Furthermore, responsive oxygen species may likewise influence sertoli cells, that influence the protein blend hardware required for separation of germ cells. This specific sort of proteins is emitted in most extreme level in typical testis during spermatids lengthening and development of sperm [37].

The improving impact of curcumin on sperm boundaries match with different past examinations [56]. recorded that; one of the conceivable ameliorative instruments of curcumin on sperm morphology, sperm check, sperm motility and sperm reasonability in grownup male Wister rodents is to search the free radicals and consequently go about as great cancer prevention agents. Curcumin has been appeared to have solid cell reinforcement action and diminishing oxidative stress.

HO. Mohammed et al., [51] contemplated the conceivable function of curcumin against changes brought about by paracetamol in testis of grown-up pale skinned person rodent and concurred with our outcome as it demonstrated noteworthy increment sperm check after co organization of curcumin with paracetamol.

The sub-atomic system by which curcumin influence sperm work isn't notable. One of the proposed conceivable ameliorative systems of curcumin on sperm boundaries is to search the free radicals as an enemy of oxidant through its phenolic, $\beta$-diketone and methoxy useful gatherings [11].

The upgrading impact of nutrient $\mathrm{C}$ on sperm check and motility could be ascribed to the defensive part of nutrient $\mathrm{C}$ on spermatogenesis that concurs with prior investigations [45] and [6] and [62].

This defensive impact of nutrient $\mathrm{C}$ can be clarified by ROS scrounger impact of the nutrient $\mathrm{C}$ as it is found in fixations 10-crease higher in original plasma than serum, securing human spermatozoa against endogenous oxidative harm by killing $\mathrm{OH}-, \mathrm{O} 2$-and $\mathrm{H} 2 \mathrm{O} 2$ radicals and forestalling sperm agglutination [34]. Nutrient $\mathrm{C}$ is likewise a significant cofactor for the hydroxylation of collagens that cause cell-cell cooperations between testicular cells, which assumes a key function in spermatogenesis, improving the separation of these cells lastly expanding the quantity of cells [10] and [23]

As to level outcomes, our examination indicated nonhuge diminishing in the mean testosterone level following 63 days of meloxicam organization when contrasted with control gathering, curcumin treated gathering and nutrient $\mathrm{C}$ treated gathering, while in both defensive gatherings [meloxicam with curcumin and meloxicam with nutrient $\mathrm{C}$ treated groups], there was non-critical ascent in mean testosterone level, simultaneously, there was no huge distinction between the two defensive gatherings.

The consequences of [68] concur with our outcomes as its outcomes demonstrated no noteworthy decline in plasma testosterone in the wake of treating rodents with meloxicam for progressive 35 days. What's more, the investigation of [35] the degrees of complete testosterone and free testosterone somewhat yet not fundamentally diminished in meloxicam treated rodents contrasted with control gathering.
While in the investigation of [28] revealed that the degrees of plasma testosterone indicated a huge abatement among in meloxicam treated gatherings toward the finish of the second, fourth, eighth seven day stretch of test fair and square of serum testosterone in contrasting with control gatherings, disclosing this lessening because of the degenerative changes initiated by meloxicam on testicular tissue notwithstanding the inhibitory impact of it on gonadotrophic hormone that answerable for testosterone emission.

Most patients on NSAIDs are long haul clients of these medications and the harmful impacts of the medication give off an impression of being total with the unfriendly impacts as oxidative pressure harm in various organs showing up after delayed use [32].

Concerning of our examination about MDA test in testicular tissue, it indicated high noteworthy increment in the mean estimation of MDA levels following 63 days of meloxicam organization when contrasted with control gathering, curcumin treated gathering and nutrient $\mathrm{C}$ treated gathering. While in defensive gathering with curcumin, there was improvement showed by high huge abatement in mean estimation of MDA levels. On the opposite side, the other defensive gathering with nutrient $\mathrm{C}$ indicated likewise improvement that showed by a high critical decline in mean estimations of MDA levels. While by contrasting aftereffects of both defensive gatherings, more reduction in mean estimation of MDA levels in defensive gathering with curcumin than defensive gathering of nutrient $\mathrm{C}$ with no huge distinction.

[50] study demonstrated that meloxicam in low and high dosages caused noteworthy rise in the degree of MDA contrasted with control gathering. This showed meloxicam incites oxidative worry since MDA, which is the last item in lipid peroxidation measure, is considered as oxidative pressure marker. Meloxicam disposal require digestion that is responsive oxygen species-creating measure. The expanded creation of free oxygen radicals and MDA by meloxicam and the resultant OS brought about by the consumption of GSH stores have been distinguished as significant supporters of the pathogenesis of gastric mucosal injury [20].

[33] study uncovered curcumin was lessen oxidative pressure prompted by both methotrexate or meloxicam and its blend by means of securing cells against freeradical harm and giving a fractional insurance against methotrexate-meloxicam instigated hepatotoxicity and nephrotoxicity. Curcumin gave huge reduction of MDA level in the hepatic and renal tissues.

The part of curcumin in diminishing MDA was accounted for by [7] as curcumin can go about as a free extreme forager and an inhibitor of MDA creation. Curcumin has been recommended to go about as an activator of the sirtuins [SIRT] intracellular administrative protein; SIRT1 and SIRT3. Different investigations recommend that SIRT1 and SIRT3 restrain OS in cells decreasing MDA.

Past investigations revealed that meloxicam caused critical rise in the degree of malondialdehyde [MDA] in liver homogenate contrasted with control and nutrient $\mathrm{C}$ 
alone, while a huge lessening has been recorded in the meloxicam treated gathering in the wake of treating with nutrient $\mathrm{C}$ in contrast with meloxicam alone [3] and [9]

As to of our examination about GSH, SOD, GPx measure in testicular tissue, the current investigation demonstrated high huge lessening in the mean estimation of their levels following 63 days of meloxicam organization when contrasted with control gathering, curcumin treated gathering and nutrient $\mathrm{C}$ treated gathering, while in defensive gathering with curcumin, there was improvement showed by high noteworthy ascent in mean estimation of GSH, SOD, GPx levels, while, in the other defensive gathering with nutrient $\mathrm{C}$, there was likewise improvement showed by a critical ascent in mean estimation of GSH level and high huge ascent in SOD and GPx levels, while by looking at aftereffects of both defensive gatherings, more ascent in mean estimation of GSH, SOD, GPx level in defensive gathering with curcumin than defensive gathering of nutrient $C$ with a huge distinction.

[69] study harmonize with our outcome as it discovered huge decrease in GSH, SOD and GPx levels in testicular tissue of rodents treated with meloxicam for five weeks as contrasted and control gathering.

Likewise, rehashed adminstration of meloxicam caused huge lessening in GSH levels in gatric mucosa and blood tests as contrasted and control bunch [20] and [50].

The instrument by which meloxicam iduces lipid peroxidation with diminished degrees of endogenous cell reinforcement [GSH] might be because of chelation of other regular tissue cancer prevention agents as recommended by [2] study that proposed the oxidative harm during peroxicam affront might be because of capacity of as a solid chelator of zinc, copper, and manganese are fundamental components that intercede the capacity of cancer prevention agent chemicals and other physiological capacities in natural framework.

In past examinations that coducted to assess the defensive impact of curcumin against unfavorable impacts of meloxicam in rodents, meloxicam Increased lipid peroxidation that cross-joins cell reinforcement chemicals including SOD and GPx as MDA inactivates these catalysts, which brings about an expanded amassing of responsive oxygen species and disturbance of macromolecular harm. The oral organization of curcumin switched the unfavorable impacts of meloxicam remembered expanding for GSH and SOD levels [8] and [33] and [50].

[16] study that investigated curcumin taking care of may trigger biosynthesis of GSH by upgrading the record of qualities for glutamate cysteine ligase, the raterestricting chemical in GSH blend. While [24] study disclosed curcumin capacity to rummage free radicals, connecting with oxidative course, extinguishing oxygen radicals, hindering oxidative catalysts and chelating metal particles restrains lipid peroxidation and reestablishes the cancer prevention agent status. Likewise, curcumin was appeared to instigate a few enzymatic cell reinforcements, for example, SOD and GPx, and actuate again combination of GSH.
Nutrient $\mathrm{C}$ likewise may upgrade hostile to oxidant action in tissue by improving tissue cancer prevention agents as GSH levels. Past examination has shown that the mean every day dietary admission for nutrient $\mathrm{C}$ among sound youthful grown-ups was decidedly connected with an expansion in plasma nutrient $\mathrm{C}$ level and serum cancer prevention agents boundaries, including GSH, all out cell reinforcement limit, and thiols [74] and [53].

The conceivable instrument of nutrient $\mathrm{C}$ as defensive factor in meloxicam poisonousness might be because of its cell reinforcement impact, which hinders the actuation of meloxicam into the responsive structure. Likewise, ascorbic corrosive is a powerful forager of ROS in plasma and extracellular compartments of the tissue by expanding SOD and GPx compounds [9] and [34]

[61] study revealed that peroxicam incited hepatotoxicity through peroxidative debasement of the lipid film is diminished by expanded liver cell reinforcement exercises as ascorbic corrosive and flavonoids that expanded liver GSH.

Our histopathological discoveries of meloxicam treated gathering for 63 days demonstrated that changed testicular cell reinforcement status was related with the testicular harm. Seminiferous tubules with some spermatogonia masterminded nearby the cellar film however not all together as in charge male rodents. They seemed dissipated and just halfway encompassing the whole seminiferous tubule. Huge numbers seminipherous tubules indicated obvious hypocellularity of all phases with diminished numbers and at times missing of spermatids and develop sperms, cylindrical degeneration and intercellular vaculaization. The interstitial tissue between tubules demonstrated indicated many expanded blocked veins, fibrosis like appearance and testimony of hyaline material

The investigation of [69] concurred with our outcome as the histopathological examination In the testis of rodents treated with meloxicam for 35 days uncovered many harmed tubules, interstitial vascular clog, and expanded centralization of connective tissue while some seminiferous tubules containing close ordinary spermatogenetic cells and progressing spermatogenesis.

Also, [35] study detailed that histopathology of balls was solid proof for the impact of meloxicam on spermatogenesis supporting our histopathological discoveries of the testis. His investigation demonstrated a central spermatogenic capture happened in rodents accepting the most elevated portion of meloxicam. Besides, a void epididymal channels from sperms in treated rodents was taken note.

Histopathological adjustments in testicular tissue might be clarified by the going with changes in cell reinforcements' boundaries that propose the nearness of oxidative worry as it is notable that testis and spermatozoa are amazingly touchy to oxidative pressure instigated harm. Free radicals initiate lipid peroxidation of layer bound polyunsaturated acids of mammalian testicles and different biomembranes prompting weakness of the film uprightness and degeneration of seminiferous 
tubules. Accordingly, testicular decay and tissue degeneration happen [36], 2011 and [50].

As to results, curcumin accompanying with meloxicam much ensured design of seminefrous tubules; there was close to typical engineering of seminefrous tubules; germ cells encompassing the entire seminiferous tubule showing up mitotically dynamic and demonstrated various phases of development, masterminded in numerous layers from cellar film toward the lumen of the tubules, not many central spermatogenic capture saw with considerably less fibrosis like appearance and blocked veins of interstitial tissue.

The consequences of current investigation were upheld by aftereffects of [33] that demonstrated the compelling part of curcumin in enhancement of the histopathological adjustment of liver and kidney tissues brought about by meloxicam. Curcumin lessened the cell vaculation and corruption in hepatic and renal tissues. Curcumin can balance out the respectability of cell films or advance the recovery of harmed cells forestalling cell harm [72]\& [51]

Our outcomes demonstrated that nutrient $\mathrm{C}$ attending treatment with meloxicam produce less improvement in histopathological discoveries that was distinguished in contrast and meloxicam and curcumin treated gathering, as most seminiferous tubules show up with close to typical engineering of seminiferous tubules, close to ordinary spermatogenic cells and continuous spermatogenesis with expanded spermatides in lumen while a few tubules gave some loss of typical design with intercellular vacuoles, less quantities of spermatocytes and sperms filling lumen and less fibrosis like appearance and blocked veins of interstitial tissue.

The aftereffects of [3] demonstrated the viable function of nutrient $\mathrm{C}$ in improvement of the histopathological change of liver tissue brought about by meloxicam. Nutrient $\mathrm{C}$ decreased the cell vaculation and corruption in hepatic tissue. Such defensive impact of nutrient $\mathrm{C}$ against meloxicam-actuated tissue harm was clarified by the oxidation - antioxidation system since nutrient $\mathrm{C}$ is a solid cell reinforcement operator.

Gathering of lipid peroxidation harms cell layers causing destabilization of Sertoli cell layers, which brings out debilitation of their joints with germ cells, loss of spermatocytes and spermatids, and early arrival of spermatozoa. Nutrient $\mathrm{C}$ displays a reasonable defensive activity on the rodent testis presented to oxidative pressure, likely through adjustment of Sertoli cell films [4].

As respect ultrastructure changes in this investigation, electron microscopial assessment of the testicular examples of the rodents treated with meloxicam demonstrated thick wavy cellar layer, Sertoli cells showed up with cytoplasmic vacuoles and swollen mitochondria and electron thick bodies, Spermatogonia showed up with consolidated chromatin and cytoplasmic vacuolation and perinuclear spaces and swollen vacuolated mitochondia, spermatocytes showed up with cytoplasmic vacuolation and perinuclear spaces and swollen vacuolated mitochondia, likewise it indicated declined spermatid with misshaped acrosomal top and electron thick bodies and swollen vacuolated mitochondia, while sperms showed up with dissaranged flagellar segment in cross area and leidyg cells indicated cytoplasmic vacuolation. Meloxicam and curcumin treated gathering indicated checked improvement in roughly all these ultrastructure changes, while meloxicam and nutrient $\mathrm{C}$ treated gathering demonstrated likewise improvement these ultrastructure changes however with lesser degree.

The ultrastructural impacts of meloxicam on testicular cells were like those brought about by paracetamol high rehashed dosages that repoted by [75] and [76] examines that indicated loss of contact between cells, regions of fracture of the Sertoli cell augmentations, stamped vacuolization, extending of the intercellular space with numerous fibroblast cells, and adjustment of the storm cellar film in specific territories, enormous lipid beads [electron thick bodies] were found in the Sertoli cells and Spermatids with inadequate acrosomes were moreover observed.

\section{Conclusion}

In end, this investigation uncovered that oral admission of meloxicam for extensive stretches prompts conceptive harmfulness in grown-up male pale skinned person rodents showed by decline in testicular capacities in type of diminished sperm tally, sperm motility and serum testosterone level just as upset oxidative pressure biomarkers. In addition, auxiliary and ultrastructural changes of testicles were taken note. Organization of nutrient $\mathrm{C}$ or curcumin improved these impacts.

\section{Recommendations}

- on the consequences of this investigation, the accompanying rules are suggested:

- Establishing far reaching state funded instruction in regards to the wellbeing risks of ceaseless meloxicam and different NSAIDs consumption with an uncommon worry about its conceptive poisonous impacts particularly without doctor discussion.

- Meloxicam long haul use is smarter to be kept away from in youthful guys with conceptive issues.

- Regular assessment of testicular capacities as testosterone level, semen investigation is enthusiastically suggested in patients on meloxicam treatment side.

- Dietary admission of curcumin and nutrient C supplements with increment admission of food and natural products plentiful in nutrient $\mathrm{C}$ is fundamental as it functions as a powerful cell reinforcement that can turn around oxidative harm inside the testiculartissue.

\section{References}

[1] A. M, Abd El Nasser, A. H, Bogzil , O. S, Mogoda, Adverse Effects Of Carprofen And Meloxicam In Male Rats. Br J Pharm Med Res, Vol.4, PP.1979,2019.

[2] A. Abdeen, M. Aboubakr, D. Elgazzar, Rosuvastatin attenuates piroxicam-mediated gastric ulceration and 
hepato-renal toxicity in rats. Biomed. Pharmacother, Vol.110, PP.895-905, 2019.

[3] MY. Ahmed, JH. Abdul-Fattah, FM. Aziz, The protective role of vitamin $\mathrm{c}$ against the hepatotoxic and nephrotoxic effect of meloxicam in male mice. $\mathrm{J}$ Pharm Biol Sci, Vol.10 (5), PP. 69-73, 2015.

[4] Aitken RJ and Roman SD, Antioxidant systems and oxidative stress in the testis. Oxid Med Cell Long, Vol.1(1), PP. 15-24, 2008.

[5] EH. Aksu, M. Özkaraca, FM. Kandemir, [Mitigation of paracetamol-induced reproductive damage by chrysin in male rats via reducing oxidative stress. Andrologia, Vol.48 (10), PP .1145-1154, 2016.

[6] WM. Al-Amoudi, Protective effect of vitamin C against carbofuran-induced testicular toxicity in albino mice. J. Am. Scivol, Vol.8(1), PP. 335-341, 2012.

[7] M. Alizadeh, S. Kheirouri, Curcumin reduces malondialdehyde and improves antioxidants in humans with diseased conditions: a comprehensive meta-analysis of randomized controlled trials. BioMedicine, Vol.9(4), PP. 10-22, 2019.

[8] A. Al-Wahed, Protective Effect of Curcumin against Adverse Effects of Meloxicam in Rats. Benha Vet Med J, Vol.33(20), PP. 58-64, 2017.

[9] HM. Amin, MA. El-Feki, AA. Abdalla, Hematological and Biochemical Effects of Meloxicam in Male Albino Rats. Curr Sci Int, Vol.6[1], PP. 23-3, 2017.

[10] C. Angulo, R. Maldonado, E. Pulgar, Vitamin C and oxidative stress in the seminiferous epithelium. Biol Res, Vol.44(2), PP. 169-180, 2011.

[11]P. Aparnak, A. Saberivand, Effects of curcumin on canine semen parameters and expression of NOX5 gene in cryopreserved spermatozoa. Vet Res Forum, Vol.10 (3), PP. 221, 2019.

[12]E. Baggaley, S. Nielsen, D. Marples, Dehydration induced increase in aquaporin-2 protein abundance is blocked by nonsteroidal anti-inflammatory drugs. Americ. J. Physiol.-Renal Physiol, Vol .4, PP. 10511058, 2010.

[13]E. Barati, H. Nikzad, M.Karimian, Oxidative stress and male infertility: Current knowledge of pathophysiology and role of antioxidant therapy in disease management. Cell. Mol. Life Sci, PP.1-21, 2020.

[14]JH. Bearden, JW. Fuquay, Applied animal reproduction. Reston publishing company inc. A prentice Halls Company Virginia, PP. 341-345, 1984.

[15]ND. Bhadja, subacute oral toxicity study of meloxicam in westar rats [Doctoral dissertation, Anand Agricultural University, Anand]. http://krishikosh.egranth.ac.in/handle/1/5810031331, 2007.

[16] SK. Biswas, D. McClure, LA. Jimenez al, Curcumin induces glutathione biosynthesis and inhibits NF- $\mathrm{BB}$ activation and interleukin- 8 release in alveolar epithelial cells: mechanism of free radical scavenging activity. Antioxid Redox Signal, Vol.7 (1-2), PP. 3241, 2005.

[17] K. Brune, P. Patrignani, New insights into the use of currently available non-steroidal anti-inflammatory drugs. J Pain Res, Vol.105, PP.44-90, 2015.

[18] D. Burukoglu, C. Baycu, F. Taplamaciogluet, Effects of nonsteroidal anti-inflammatory meloxicam on stomach, kidney, and liver of rats. toxicol ind health, Vol.32(6), PP. 980-986, 2016.

[19] U.B. Das, M. Mallick, JM. Debnath,. Protective effect of ascorbic acid on cyclophosphamideinduced testicular gametogenic and androgenic disorders in male rats. Asian J Androl, Vol.4, PP. 201-207, 2002.

[20]B. Demircan, G. Çelik, H. Süleyman,. Effects of indomethacin, celecoxib and meloxicam on glutathione, malondialdehyde and myeloperoxidase in rat gastric tissue. The Pain Clinic, Vol.17(4), PP. 383-388, 2005.

[21]EK. Dirican, Y. Kalender, Dichlorvos-induced testicular toxicity in male rats and the protective role of vitamins C and E. Exp Toxicol Pathol, Vol.64(78), PP. 821-830, 2012.

[22] E. Drobnis, A. K. Nangia, Pain medications and male reproduction. In Impacts of Medications on Male Fertility, pp. 39-57, Springer, Cham, 2017.

[23]UB. Ekaluo, EV. Ikpeme, YB. Ibiang, Attenuating Role of Vitamin C on Sperm Toxicity Induced by. J Biol Sci, Vol.13[4], PP. 298-301, 2013.

[24]DS. El-Agamy, Comparative effects of curcumin and resveratrol on aflatoxin B 1-induced liver injury in rats. Arch Toxicol, Vol.84 (5), PP. 389-396, 2010.

[25] G. El-Akabawy, NM. El-Sherif, Protective role of garlic oil against oxidative damage induced by furan exposure from weaning through adulthood in adult rat testis. Acta histochemica.vpl.118 (5), PP. 456463, 2016.

[26]IM. El-Ashmawy, AA. Mandour, Studies on the influence of ivermectin on reproductive organs and liver function in male rabbits. In Third Vet Med Conf. Zagazig: Egypt, 1996.

[27]ZK. El-Maddawy YS. El-Sayed, Comparative analysis of the protective effects of curcumin and $\mathrm{N}$ acetyl cysteine against paracetamol-induced hepatic, renal, and testicular toxicity in Wistar rats. Environ Sci Pollut Res, Vol.25 (4), pp.3468-3479, 2018.

[28] AR. El-Nakeeb, IM. El-Ashmawy, AF. El-Sawy, Effect of Meloxicam and tolfenamic acid on some reproductive aspects of male rats. Alex J Vet Sci, Vol.34 (1), PP. 225-234, 2011.

[29] MB. Frungieri, RS, Calandra, A. Mayerhofer, Cyclooxygenase and prostaglandins in somatic cell populations of the testis. Reproduction, Vol.149 (4), PP. 169-180, 2015.

[30]RS. Greenberg, RS. Daniels, WD. Flanders, JW. Eley, JR. Boring, Diagnostic testing. In: Medical epidemiology. 3rd ed., McGraw-Hill, New York, NY, pp. $77-89,1996$. 
[31] A. A. Haq, S. Nigar, , S.Khalid, Role of antioxidant in chemotherapy related infertility. Pak J Physiol, Vol.16 (1), PP. 14-16, 2020.

[32] S. Harirforoosh, F. Jamali, Renal adverse effects of nonsteroidal anti-inflammatory drugs. Expert Opin Drug Saf, Vol.8 (6), pp.669-681, 2009.

[33] WA. Hassan, Ameliorative effects of Curcuma longa on methotrexate and meloxicam-induced hepatoxicity and nephrotoxity in rats. Sci. J., Oct. 6 Univ, Vol.4 (1), PP. 20-26, 2017.

[34] M. Inoue, A. S. A. Y. A. S. U. Protective mechanisms against reactive oxygen species. The liver: biology and pathobiology, pp. 443-459, 1994.

[35] JMY. Jaber, A. Salhab, Y.Irshaid, The Effects of Meloxicam on the Fertility of Male Rats [thesis]. Library of University of Jordan, center of thesis deposit, 2009.

[36] RD. Jadav, BJ. Patel, Toxicopathological studies of experimentally induced meloxicam toxicity in wistar rats [Rattus norvegicus]. Wayamba J Ani Sci, Vol.6, PP.870-875, 2014.

[37]E. Karaguzel, M. Kadihasanoglu, O. Kutlu, Mechanisms of testicular torsion and potential protective agents. Nat Rev Urol, Vol.11(7), PP. 391399, 2014.

[38] S. Karimi, , L. Khorsandi, F. Nejaddehbashi, Protective effects of Curcumin on testicular toxicity induced by titanium dioxide nanoparticles in mice. JBRA Assist Reprod, Vol.23(4), PP. 344.

[39] AM. Khan, S. Rampal, Effects of repeated oral administration of pazufloxacin mesylate and meloxicam on the antioxidant status in rabbits. J. Am. Assoc. Lab. Anim. Sci, Vol.53(4), PP. 399-403, 2014.

[40] AM. Khan, S. Rampal, NK. Sood, Effect of repeated oral administration of levofloxacin, enrofloxacin, and meloxicam on antioxidant parameters and lipid peroxidation in rabbits. Hum Exp Toxicol, Vol.36 (1), PP. 42-50, 2017.

[41]L. Khorsandi, M. Mirhoseini, M. Mohamadpour, Effect of curcumin on dexamethasone-induced testicular toxicity in mice. Pharm. Biol, Vol.51 (2), PP. 206-212, 2013.

[42] S. Lamberg, R. Rothstein, Laboratory Manual of Histology and Cytology. [2nd ed.], A.V.I. Publishing Company, West Port Connecticut, PP.137-140, 1978.

[43] F.Lombardo, A. Sansone, F. Romanelli, The role of antioxidant therapy in the treatment of male infertility: an overview. Asian J. Androl, Vol.13 (5), PP.690-698, 2011.

[44] M. Lonare, M. Kumar, S. Raut, Evaluation of ameliorative effect of curcumin on imidacloprid-induced male reproductive toxicity in wistar rats. Environ. Toxicol, Vol.31 (10), PP. 12501263, 2016

[45]D. MacKay, AL. Miller, Nutritional support for wound healing. Altern Med Rev, Vol.8(4), PP. 359$378,2003$.

[46] TK. Mandal, NS. Das, Correlation of testicular toxicity and oxidative stress induced by chlorpyrifos in rats. Hum Exp Toxicol, Vol.30 (10), PP. 15291539, 2011.

[47] CS. Martinez, FM. Peçanha, DS. Brum, Reproductive dysfunction after mercury exposure at low levels: evidence for a role of glutathione peroxidase [GPx] 1 and GPx4 in male rats. Reprod. Fertil. Dev, Vol.29(9), PP. 1803-1812, 2017.

[48]FB. Marwa, S. Maisa, K. Sabna, The Effect of Meloxicam and Piroxicam on the Fertility of Male Rats. IOSR J. Pharm. \& Biol. Sci, Vol.14 (5), PP. 6378, 2019.

[49] AB. Maunsbach, BA. Afzelius Biomedical Electron Microscopy: Illustrated Methods and Interpretations [1 ${ }^{\text {st }}$ Ed.], Academic Press, Son Diego, 1999.

[50] S. Mitra, A. Srivastava, S. Khandelwal, Tributyltin chloride induced testicular toxicity by JNK and p38 activation, redox imbalance and cell death in sertoligerm cell co-culture. Toxicology, Vol.314 (1), PP. 39-50, 2013.

[51]HO. Mohammed, The Possible Role of Curcumin against Changes Caused by Paracetamol in Testis of Adult Albino Rat [Histological, Immunohistochemical and Biochemical Study]. Egypt. J. Histol., Article in Press, DOI: 10.21608/EJH.2019.18599.1189, 2019.

[52]NM. Mohammed, E. El-Drieny, S. Ibrahim, Histopathological Changes in liver tissue induced by meloxicam in male mice. Int $\mathbf{J}$ Pharm Life Sci, Vol.10 (1), PP. 6059-6063, 2019.

[53] V. Montecinos, P. Guzmán, V. Barra, Vitamin C is an essential antioxidant that enhances survival of oxidatively stressed human vascular endothelial cells in the presence of a vast molar excess of glutathione. J. Biol. Chem, Vol.282 (21), PP. 15506$15515,2007$.

[54]A. Nashwa, FY. Venes, Impact of vitamin $C$ on genotoxicity, sperm abnormalities and serum biochemical alterations in deltamethrin exposed rats. Egypt J Comp Pathol Clin Pathol, Vol.21(1), PP. 168- 188, 2008.

[55]H. Oguzturk, O. Ciftci, M. Aydin, Ameliorative effects of curcumin against acute cadmium toxicity on male reproductive system in rats. Andrologia, Vol.44[4], PP. 243-249, 2012.

[56] UA. Okon, II. Utuk, Ascorbic acid treatment elevates follicle stimulating hormone and testosterone plasma levels and enhances sperm quality in albino Wistar rats. Niger Med J: J Nigeria Med Assoc, Vol.57(1), PP. 31-36, 2016.

[57]M. Picard, C. Rossier, O. Papasouliotis, Bioequivalence of recombinant human FSH and recombinant human $\mathrm{LH}$ in a fixed 2:1combination: two phase I, randomised, crossover studies. Curr Med Res Opin, Vol.24 (4), PP. 1199-1208, 2008.

[58] K. Rashid, P. C. Sil, Curcumin ameliorates testicular damage in diabetic rats by suppressing cellular stressmediated mitochondria and endoplasmic reticulumdependent apoptotic death. Biochimica et biophysica acta [BBA]-molecular basis of disease, Vol.1852(1), PP. 70-82, 2015. 
[59] T. Rasyidah, S. Suhana, H. Nur-Hidayah, Evaluation of antioxidant activity of Zingiber officinale [ginger] on formalin-induced testicular toxicity in rats. $\mathrm{J}$ Med Biol Eng, Vol.3(3), PP. 149-153, 2014.

[60] SM. Rivera-Velez, LE. Broughton-Neiswanger, M. Suarez, Repeated administration of the NSAID meloxicam alters the plasma and urine lipidome. Sci. Rep, Vol.9 (1), PP. 4303-4307, 2019.

[61]CR. Sahu, Mechanisms Involved in Toxicity of Liver Caused by Piroxicam in Mice and Protective Effects of Leaf Extract of Hibiscus rosa-sinensis L. Clin Med Insights Arthritis Musculoskelet Disord, Vol.9 , PP.9-13, 2016.

[62] S.Shabanian, F. Farahbod, M. Rafieian, The effects of Vitamin $\mathrm{C}$ on sperm quality parameters in laboratory rats following long-term exposure to cyclophosphamide. J. Adv. Pharm. Technol. Res, Vol.8 (2), PP. 73-78, 2017.

[63]P. Singh, k. Deora, V. Sankhla, Curcumin rendered protection against cadmium chloride induced testicular damage in Swiss albino mice. J Cell Mol Biol, Vol.10 (2), PP. 31-38, 2012.

[64] A. Siviero, E. Gallo, V. Maggini, Curcumin, a golden spice with a low bioavailability. J Herb Med, Vol.5 (2), PP. 57-70, 2015.

[65]A. Soleimanzadeh, A. Saberivand, Effect of curcumin on rat sperm morphology after the freezethawing process. In Veterinary Research Forum. Faculty of Veterinary Medicine, Urmia University, Urmia, Iran, Vol.4 (3), pp. 185 , 2013.

[66] C. Sostres, CJ. Gargallo, A. LanasNonsteroidal antiinflammatory drugs and upper and lower gastrointestinal mucosal damage. Arthritis Res Ther, Vol.15 (3), PP .3-11. , 2013.

[67] V.Srikanth, T.Malini , J.Arunakaran. Effects of ethanol treatment on epididymal secretory products and sperm maturation in albino rats. J. Pharmacol. Exp. Ther, Vol.288 (2), PP. 509-515,1999.

[68] SA. Sudjarwo ,and Giftania K. Wardani Sudjarwo, Protective effect of curcumin on lead acetate-induced testicular toxicity in Wistar rats. Res Pharm Sci, Vol.12 (5), PP. 381.-388.2017.

[69]B.Uzun, O.Atli, BO. Perk Evaluation of the reproductive toxicity of naproxen sodium and meloxicam in male rats. Hum Exp Toxicol, Vol.34 (4), PP. 415-429.2015.

[70]I.Villegas, C.Alarcón de la Lastra, C.La Casa,. Effect of food intake and oxidative stress on intestinal lesions caused by meloxicam and piroxicam in rats. Eur J Pharmacol, Vol.1(414), PP. 79-86, 2001.

[71]I.Villegas, CA. De La Lastra , MJ.Martín, Gastric damage induced by subchronic administration of preferential cyclooxygenase-1 and cyclooxygenase-2 inhibitors in rats. Pharmacology, Vol.66 (2), PP. 6875. ,2002.

[72]I.Villegas , M J.Martin, C. La Casa. Effects of meloxicam on oxygen radical generation in rat gastric mucosa. Inflamm. Res, Vol.49[7], PP. 361-366. ,2000.

[73]A.Vyas, H. Ram , A.Purohit. Adverse effects of subchronic dose of aspirin on reproductive profile of male rats. J. Pharm, Vol.2016, PP. 1-9,2016.

[74]MI.Waly, Z.Al-Attabi,N.and Guizani Low nourishment of vitamin $\mathrm{C}$ induces glutathione depletion and oxidative stress in healthy young adults. Prev Nutr Food Sci, Vol.20 (3), PP. 198203,2015.

[75] CL.Yano, and H.Dolder, Rat testicular structure and ultrastructure after paracetamol treatment. Contraception, Vol.66 (6), PP. 463467,2002.

[76] MM.Yousef, OK. Helal, N.and Adly, Histological study of the effect of paracetamol on the seminiferous tubules of adult rabbits: light and electron microscopy. Egypt. J. Histol, Vol.34 (4), PP. 790-799,2011.

[77] GM Zaied, Some pharmacodynamic properties of ivermectin in comparison with doramectin in male rats [Doctoral dissertation, $\mathrm{Ph}$. D. thesis presented to Pharmacology Department, Faculty of Veterinary Medicine Alexandria University, Egypt]. Alex. J. Vet. Sci, Vol.47 (1), PP. 119-128,2004.

[78] L.Zhao,Q.Gu, L. Xiang. Curcumin inhibits apoptosis by modulating $\mathrm{Bax} / \mathrm{Bcl}-2$ expression and alleviates oxidative stress in testes of streptozotocin-induced diabetic rats. Ther Clin Risk Manag, Vol.13, PP. 1099,2017. 